\title{
HYDRODYNAMIC TESTING OF A HIGH PERFORMANCE SKIFF AT MODEL AND FULL SCALE
}

\author{
A. H .Day \\ University of Strathclyde, Glasgow, Scotland \\ P. Cameron \\ University of Strathclyde, Glasgow, Scotland
}

\author{
S. Dai \\ University of Strathclyde, Glasgow, Scotland
}

Manuscript received

\begin{abstract}
This study examines the hydrodynamic performance of a high performance skiff hull using three different physical testing techniques which may be used in early stage design for assessment of the upright resistance of sailing vessels. The hull chosen as a benchmark form is a high-speed hard-chine sailing dinghy, typical of modern trends in skiff design, and is broadly similar to some high performance yacht hulls. The $4.55 \mathrm{~m}$ hull was tested at full scale in a moderate size towing tank, at 1:2.5 scale in the same tank, and at full-scale by towing on open water. The work presented here builds on the study of Day \& Cameron (2017), with the model tests repeated and re-analyzed in the present study and additional results presented.
\end{abstract}

The challenges of full-scale open-water testing are discussed and several potential improvements in practice are identified for future work. Results show that the open water testing broadly matches well with model-scale tank testing, with the mean discrepancy in the measured resistance between the two around $4 \%$ over the speed range tested after correction for the presence of the rudder. Agreement is initially less good for the full-scale hull in the tank for higher speeds, both for resistance and trim. ITTC guidelines suggest that blockage may be an issue for the full-scale boat in this size of tank; comparison of the results suggests that blockage, and/or finite depth effects for the full-scale hull in the tank present a substantial problem at the higher speeds. A correction approach for the wave resistance of the full scale results using a calculation based on a linear thin ship theory is effective in this case, and results show that the full scale and model scale tests agree satisfactorily for the majority of the speed range after this correction.

In addition to upright resistance in calm water, results are presented for the impact of small waves, the addition of the rudder, and variations in displacement and trim on resistance for a skiff hull. Finally, the results are compared with predictions from the well-known Delft series regression equations, Savitsky's methods, and a thin ship calculation. The thin ship approach gives good agreement for the case in which the hull is trimmed bow-down and the transom is not immersed, while the Savitsky pre-planing approach gives good agreement for the level trim case. The Delft series and Savitsky planing hull approaches do not give good agreement with physical measurements.

Keywords: Hydrodynamics, tank testing, resistance, skiff, 


\section{INTRODUCTION}

Large-scale tank testing at high speeds inevitably requires the use of a large, and hence costly, towing tank, which in some cases may cost many thousands of Euros per day. In many sailing vessel design applications, the cost of such a test campaign will be difficult to justify, especially at the early design stages. The present study explores the relative merits of three different moderate-cost approaches to physical measurement of the resistance of high performance sailing vessels by directly comparing results obtained for the same hull design using these approaches. These involve testing:

i) a moderate-scale model in a moderate-scale test tank

ii) a large (or full) scale model in a moderate-scale test tank

iii) a large (or full) scale model by towing behind a powerboat on open water.

In the present study all tank tests were carried out in the towing tank of the Kelvin Hydrodynamics Laboratory at the University of Strathclyde in Glasgow. The tank is $76 \mathrm{~m}$ long, $4.6 \mathrm{~m}$ wide and $2.5 \mathrm{~m}$ deep, with a typical water depth of $2.1 \mathrm{~m}$. The carriage is capable of speeds of up to $4.6 \mathrm{~m} / \mathrm{s}$. The towing system is entirely conventional, with the model free to heave, pitch and roll, and constrained in surge, sway and yaw. It should be noted that a larger towing arrangement was used for the full-scale tests due to the increased requirements for stiffness. In both cases the towing post was counter-balanced to avoid any changes in model displacement resulting from the weight of the post. In the tests described here, the resistance was measured using a strain gauge load cell, while sinkage and trim were measured using linear variable displacement transducers (LVDTs). This can be regarded as fairly typical of a moderate-scale test tank.

The vessel chosen is a high-performance single-handed sailing dinghy known as a Musto Skiff (see Figure 1). The hull form is typical of a modern skiff form with an overall length of $4.55 \mathrm{~m}$, a single chine, and relatively flat sections between the keel and chine and between the chine and deck edge. The dinghy has a relatively large full-battened mainsail with an area of $11.08 \mathrm{~m}^{\wedge} 2$ and an asymmetric spinnaker of $15.50 \mathrm{~m}^{\wedge} 2$. The all-up weight of the boat in sailing condition is $82.5 \mathrm{~kg}$; the powerful rig combined with light weight allows speeds of over 20 knots. The displacement condition in the present study assumes an $80 \mathrm{~kg}$ sailor wearing $5 \mathrm{~kg}$ of clothing. The key details of the boat are shown in Table 1. This table assumes the boat is trimmed in either of two conditions.

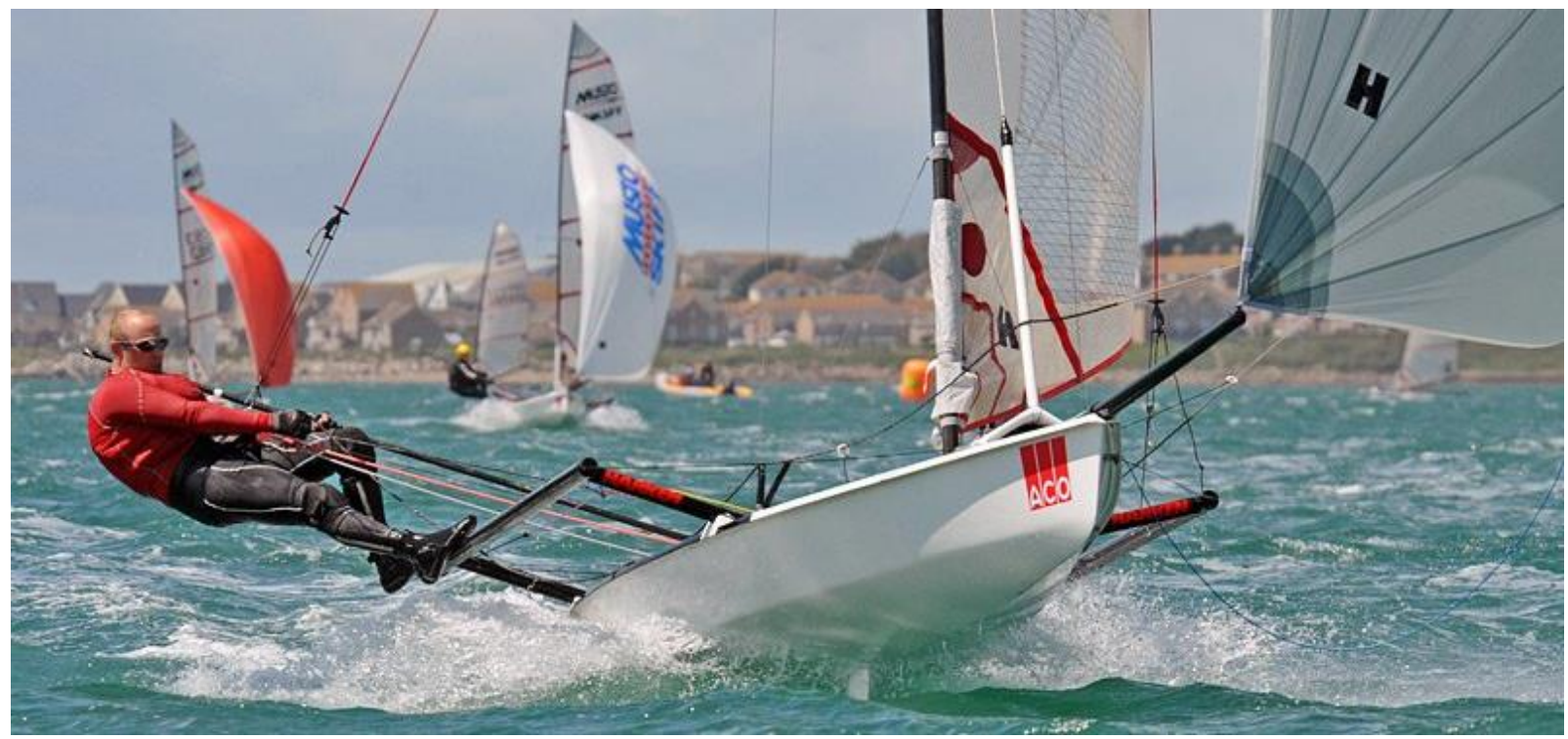

Figure 1. The Musto Skiff 
In the first condition, the vessel is trimmed slightly bow-down, so that the transom is just touching the water surface with the boat at rest. This is a typical sailing condition at low speeds in light winds. In the second condition, the aft section of chine is level. In this condition the transom is immersed; this represents a typical upwind sailing condition in moderate wind strengths. More details of the design can be found on the class website (www.mustoskiff.com).

For vessels of the size of sailing dinghies, it is possible to test at full-scale; the results of such tests may inform dinghy designers as well as researchers wishing to assess and improve performance prediction approaches such as velocity prediction programs (VPPs). However, an additional application is also considered to be of interest here: the Musto Skiff was chosen because the hull proportions as well as the hull-form shape of the boat are broadly similar to some modern high performance maxi yachts. Hence a full-scale Musto Skiff, as well as being of interest in itself, can also reasonably be regarded as generally representative of a large-scale model of a high performance skiff-like maxi yacht.A moderate-cost approach to large-scale model testing of high performance yachts could be of interest to yacht designers at the early concept design stage if it could be shown to be sufficiently accurate. The key challenges of the different possible approaches and the details of the methodology adopted in each case are discussed in the following sections.

Table 1. Typical Musto Skiff main particulars in two test conditions

$\begin{array}{llll} & \begin{array}{l}\text { "Transom- } \\ \text { touching" }\end{array} & \begin{array}{l}\text { "Chine- } \\ \text { level" }\end{array} & \\ \text { Displacement } & 167.5 & 167.5 & \mathrm{~kg} \\ \text { WL Length } & 4.514 & 4.500 & \mathrm{~m} \\ \text { WL Beam } & 0.891 & 0.941 & \mathrm{~m} \\ \text { Draught } & 0.146 & 0.127 & \mathrm{~m} \\ \text { Wetted Area } & 2.979 & 3.080 & \mathrm{~m}^{\wedge} 2 \\ \text { Max section area } & 0.063 & 0.060 & \mathrm{~m}^{\wedge} 2 \\ \text { Waterplane Area } & 2.728 & 2.903 & \mathrm{~m}^{\wedge} 2 \\ \text { Prismatic coefficient } & 0.585 & 0.622 & \\ \text { Max Section area coefficient } & 0.581 & 0.591 & \\ \text { Waterplane area coefficient } & 0.678 & 0.686 & \\ \text { LCB from FP (+ve aft) } & 49.5 \% & 57.5 \% & \% \text { Lwl } \\ \text { LCF from FP (+ve aft) } & 57.2 \% & 61.5 \% & \% \text { Lwl }\end{array}$

\section{MODERATE-SCALE MODEL TESTING IN A MODERATE-SCALE TEST TANK}

\section{Introduction}

Model testing in a moderate-scale towing tank is of course the most conventional approach to moderate-cost testing of a high performance hull. The methodology both for testing and extrapolation is well-established and set out through procedures established by bodies such as the ITTC Resistance Committee (ITTC (2008)), and the equipment required is essentially standard. However relatively few tank tests of scaled sailing dinghies, and in particular, tests of this type of skiff hull have been published. 
Day and Nixon (2014) tested a model Laser dinghy at a scale of 0.48 ; however the Laser has a conventional moderate performance hull, and the testing challenges are rather different from a high performance skiff. A two-person skiff design, the Aura, was tested at the Universities of Strathclyde and Newcastle in 2012 (see Viola et al. (2014)) as a 1/4 scale model of length $1.19 \mathrm{~m}$, and all-up weight of $3.5 \mathrm{~kg}$. The tests described focused on the effect of trim on resistance at model scale.

\section{Model Sizing}

It is well-known that the use of a smaller scale model (i.e. larger scale ratio) allows higher full-scale speeds to be achieved, while model making costs will often be less than the equivalent costs for larger models (though not necessarily in proportion to size). Once models become sufficiently small, manufacture of models with sufficient stiffness at the light weights involved starts to become a challenge, and more advanced manufacturing technologies may be required, pushing up costs. For example the Aura model, built at Ovington Boats, was manufactured in carbon fiber from a CNC-milled mold in order to achieve the target model weight.

By choosing the model size to "fit" the tank, the blockage ratio (defined as the maximum section area of the boat / cross section of the tank) may be kept within a range typical of modern tank-testing practice, and therefore can be regarded as amenable to accurate correction. However many blockage correction approaches generally recommended have been derived for conventional ships operating at moderate speeds and may not be reliable for high speed planing vessels.

A second problem which may occur in moderate-scale tanks at high speeds, even with a scale model, is the influence of water depth on wave-pattern resistance when depth Froude numbers approach unity. The wave pattern resistance may vary substantially at high subcritical, trans-critical and super-critical depth Froude Number.

The ITTC procedure 7.5-02-05-01 "Testing \& Extrapolation Methods: High Speed Marine Vehicles: Resistance Test" (2017) quotes several simple guidelines for assessing whether blockage is likely to be an issue for planing hulls, without giving details of references. The key guidelines identified by the ITTC can be summarized as:

- $\quad$ tank width should be greater than 7 times model waterline beam (due to Savitsky)

- $\quad$ tank width should be greater than 2 times the model length (due to Muller-Graf).

- $\quad$ tank depth should be greater than 0.8 times the model length (due to Muller-Graf).

This last guideline seems rather simplistic, since it is perfectly possible (and quite likely for a boat of this performance) to achieve high depth Froude numbers whilst still satisfying this rule. The approach of Tamura (1972) was initially investigated as suggested in the ITTC procedure for resistance tests for conventional ships (2017). This is not specifically intended for high speed vessels, but does include a simple correction for finite depth effect. However, the form of the correction suggests it should not be used for trans-critical or supercritical depth Froude Number tests. An approach based on thin ship theory was ultimately adopted in the present study with some success.

\section{Extrapolation}

There are several challenges related to extrapolation which may be of particular interest in this context. The first is that of turbulence stimulation. Conventional approaches such as those recommended by the ITTC involving the use of studs, trip wires, or sand strips have been validated for large models of low-speed ships, but may be less reliable for high-speed vessels. As models become smaller the ITTC recommendations for stud size, separation, 
and location appear increasingly unsuitable as the number of studs reduces to single figures, and the studs become relatively large compared to the hull, requiring stud drag correction (see for example Day et al. (2011)). Different approaches to turbulence stimulation may thus be required.

A particular challenge occurs with planing vessels for which the forward extent of the wetted length varies substantially with speed, so that turbulence stimulation cannot be in the correct location for the whole speed range unless the stimulation device is moved as speed is varied. An alternative approach was used by Viola and Enlander (2013) in which a probe is towed forward of the model in order to stimulate turbulence in the onset flow. This has the disadvantage of generating some small waves in the otherwise still water which can add significantly to the resistance. The effect of waves is discussed in a later section.

Some insight into the challenges may be gained from a study of turbulence stimulation for high-speed slender catamaran ferries through a series of "geosim" tests (Bertorello et al. (2003)); one conclusion drawn was that tests with models smaller than about $2.0 \mathrm{~m}$ the resistance could not be considered reliable even where detailed corrections for stud drag were considered. However, with models larger than $2.0 \mathrm{~m}$ it was concluded that turbulence stimulation was not required.

A second challenge relates to the wetted area used to estimate the viscous resistance. This can vary substantially when the boat is planing (as shown in Figure 1), and considerable extra effort is required to estimate the running wetted area, using underwater cameras, paint techniques or other technology. Use of the static wetted area in cases for which the wetted area is reduced due to planing will lead to an overestimation of the viscous resistance at model scale and hence incorrect extrapolation of the viscous and wave pattern components.

A final challenge relates to the form factor; for a skiff hull such as the Musto Skiff with an immersed transom, the standard Prohaska test at normal sailing trim may be unreliable, since the transom will be "wet" at the low speeds of the Prohaska test but "dry" at sailing speeds. Hence the flow in the Prohaska test is not representative of the flow in the sailing condition. This may be addressed by conducting the Prohaska test with the vessel trimmed bow-down so that the flow detaches smoothly from the transom (see Couser et al. (1997)); however, this has the disadvantage that the displaced shape of the hull does not correctly represent the sailing condition.

\section{Present Study}

In the present study the model-scale tank tests were conducted using a model constructed at a scale of $1: 2.5$, yielding a model of overall length of $1.82 \mathrm{~m}$. This size was a compromise, allowing a good range of full-scale speeds, whilst being close to meeting the suggested criterion for minimum length suggested by Bertorello (2003). The model comfortably met the three criteria for blockage / water depth as described above, with tank width $>12 \times \mathrm{Bwl}$ (compared to ITTC target of $7 \times \mathrm{Bwl}$ ), tank width $>2.5 \times \mathrm{Lwl}$ (compared to target of $2 \times \mathrm{Lwl}$ ), and tank depth $>1.1 \times \mathrm{Lwl}$ (compared to target of $0.8 \times \mathrm{LWl}$ ).

In the first instance it was originally intended to build the physical model from a CAD model generated from measurements from the full-scale dinghy. These measurements were made using a Qualisys optical motion capture system. The model generated from this process was used in the initial analysis of the full-scale data. However, the Musto Skiff builders later kindly supplied a lines plan for the boat, and the CAD model used to build the physical model was generated from this plan in the well-known MaxSurf software (see Figure 2). 


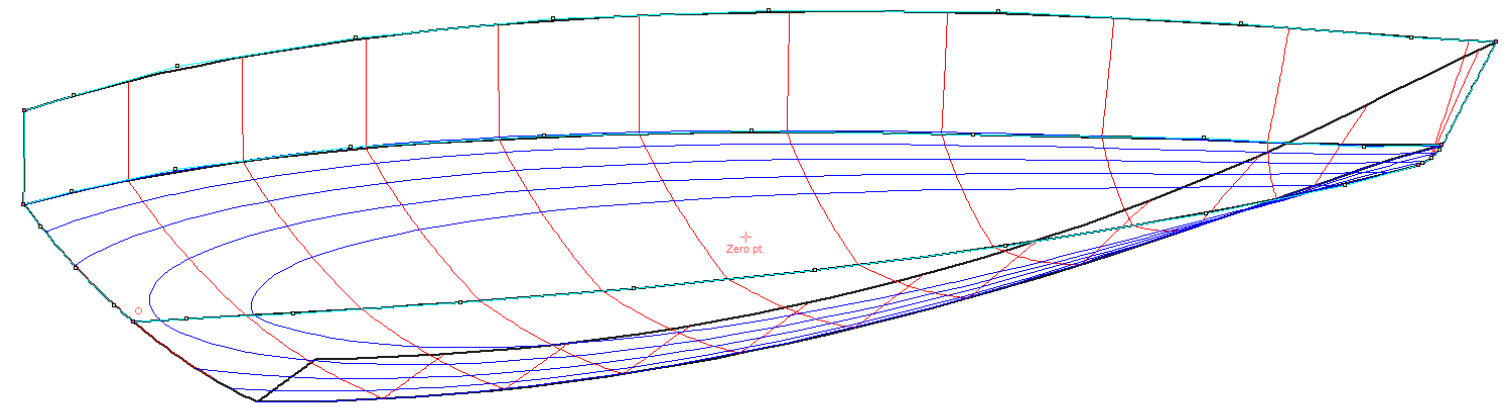

(a) 3D view

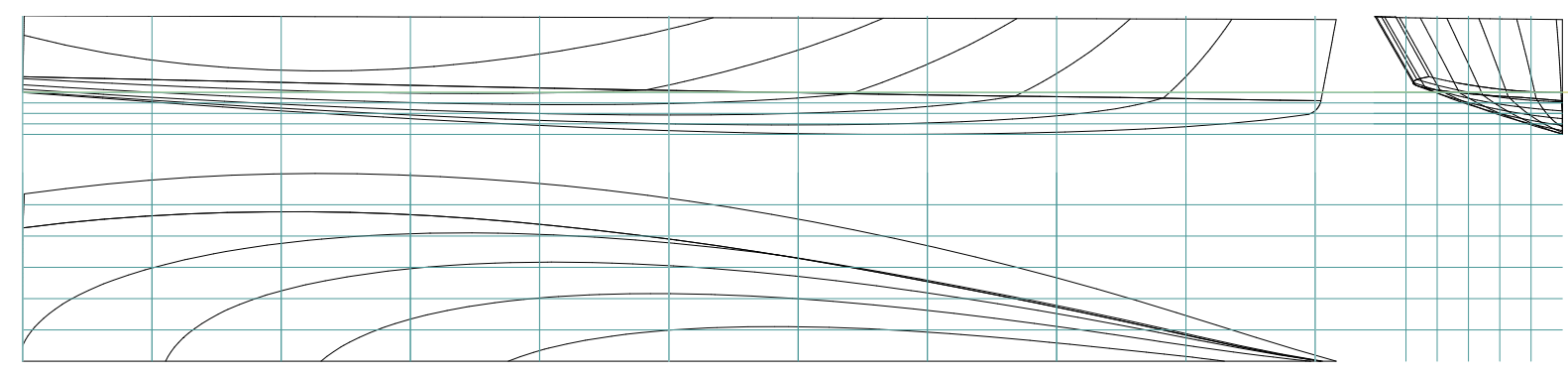

(b) Transom touching

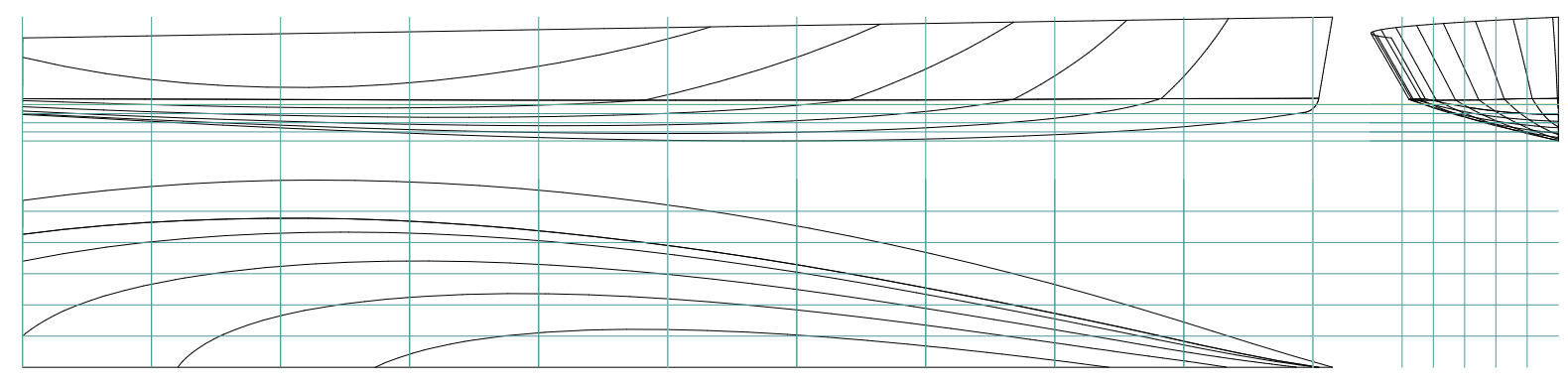

(c) Chines level

Figure 2. Final CAD model generated

The model was towed from a point corresponding as far as possible both vertically and longitudinally to the towing point utilised on the full-scale boat to allow direct comparison with the full-scale tests, in which the mast step provided a convenient and strong attachment point. No appendages were used in the model-scale testing. The scale ratio allowed testing at full-scale speeds of up to $7.25 \mathrm{~m} / \mathrm{s}$ or just over 14 knots. This is more than adequate for upwind sailing in the Musto Skiff, but slightly slow for downwind sailing in stronger winds. The blockage ratio was $0.11 \%$, which can be regarded as very small. Figure 3 shows the model in the tank, showing the towing arrangement and the differences in the attitude of the boat between the two trim conditions at a full-scale speed of 10 knots. 


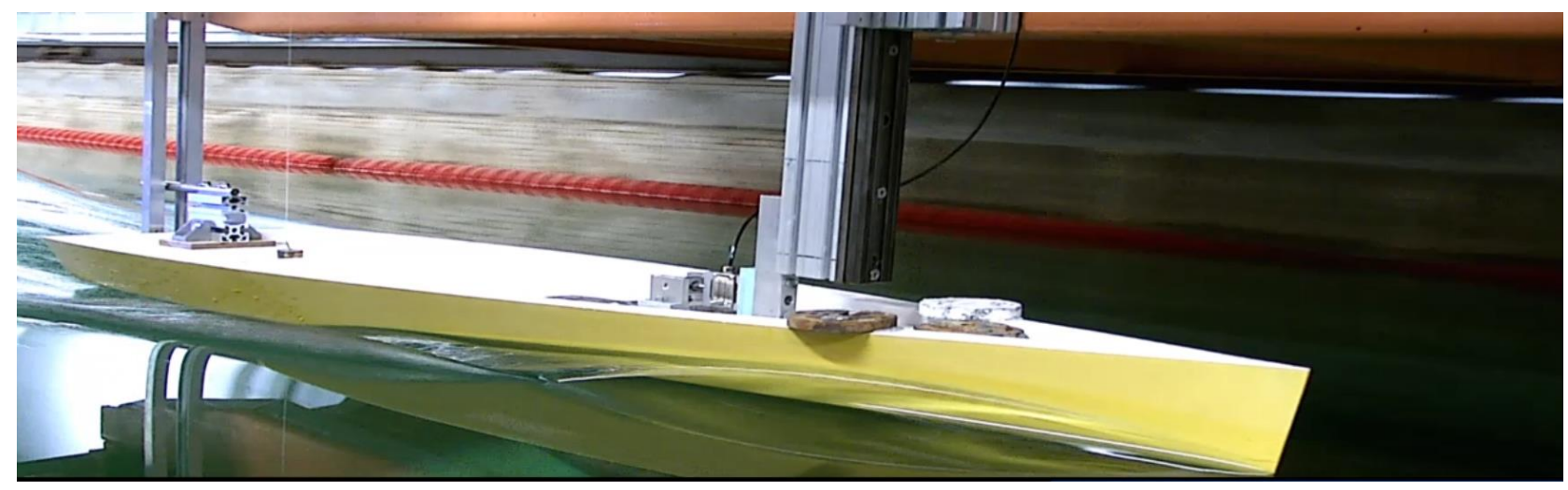

(a) Full scale speed 10 knots / Transom touching

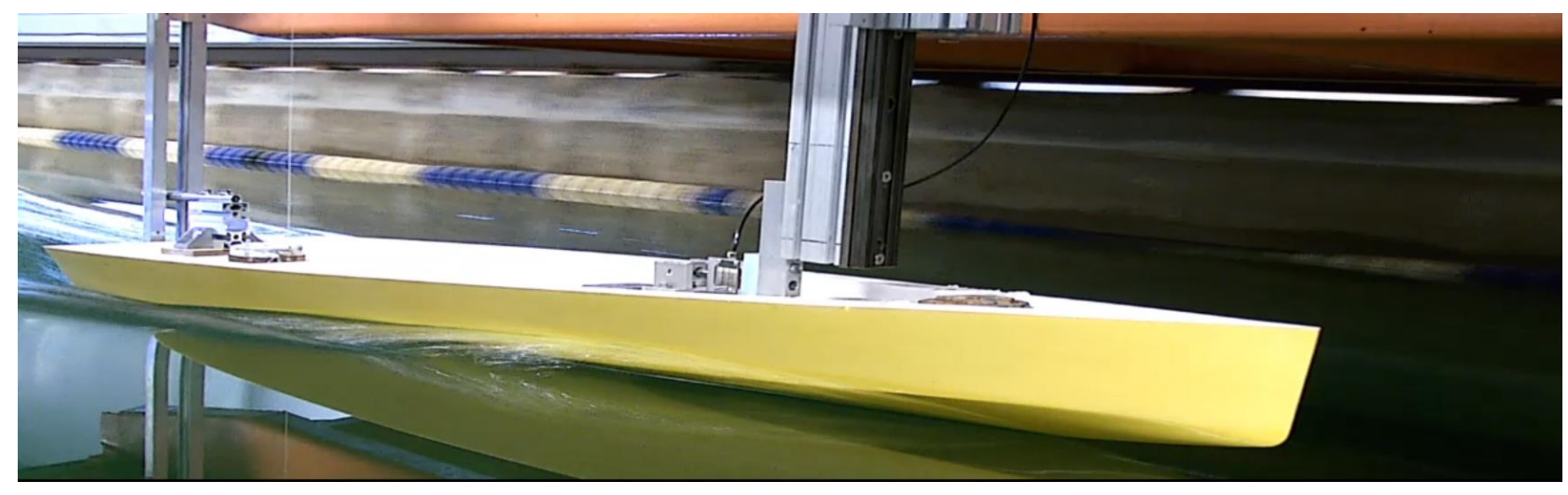

(b) Full scale speed 10 knots / Chines level

Figure 3. Scale Model in Tank

The baseline displacement and trim condition for all three test modes was the same; the model was ballasted to a (full-scale) displacement of $167.5 \mathrm{~kg}$ corresponding to an all-up boat weight of $82.5 \mathrm{~kg}$ plus a crew of weight $80 \mathrm{~kg}$ wearing $5 \mathrm{~kg}$ of clothing. The baseline trim condition for all three modes of testing was set so that the transom just touched the water. This approach to trimming had been adopted by Day and Nixon (2014) in model tests of a Laser dinghy. This trim is quite typical for a Laser over a fairly wide speed range and was adopted for the sets of tests conducted first in the present study - which were the fullscale tests. For a Musto Skiff, this trim is appropriate for relatively low speeds and light winds (as noted in the training DVD for the Musto Skiff (Stenhouse (2007))) but is regarded as a little "bow-down" for a Musto Skiff compared to typical sailing practice in moderate winds.

It is shown later (see Figure 18) that this "transom touching" condition actually results in less resistance in the tank than the more typical "moderate wind" trim with chines level up to boat speeds of around 7 knots. However in realistic sailing conditions in moderate winds and open water even small wind-generated waves can break over the bow (which has low freeboard in the "transom touching" condition), slowing the boat; hence sailors will tend to sail with slightly more bow-up trim in practice.Nonetheless the "transom touching" condition was retained as the benchmark case for the model tests in order to allow comparison with the full-scale tests. The impact of changing trim to a "chine-level" condition more typical of upwind sailing on open water was studied subsequently in the model-scale tests. 


\section{LARGE/FULL-SCALE MODEL TESTING IN A MODERATE-SCALE TEST TANK}

The key advantage of larger scale testing in both yacht and dinghy applications is the reduced uncertainties due to extrapolation from a large scale model (or full-scale dinghy) compared to a moderate-scale test. For full scale testing in particular, there are of course no significant issues related to turbulence stimulation or wetted area estimation.

In the application to sailing dinghy testing there are further advantages in that building a fullscale boat may completely eliminate the need to build a dedicated model, as the full-scale boat may be used for sailing trials as well as towing tests. Furthermore, adding appendages (e.g. daggerboard \& rudder) may well be easier in a large model or full scale boat than in a smaller model.

The typical disadvantage of testing the larger scale model is the need for use of a larger (and hence typically more expensive) tank. Several studies have examined sailing dinghies at full scale in test tanks (generally large commercial tanks). Some have been aimed at supporting Olympic campaigns and as a result studies have not been published other than via press releases. Levin and Peters (2014) report a campaign of tests of a full-scale Laser Dinghy at the SSPA towing tank $(260 \mathrm{~m} \times 10 \mathrm{~m} \times 5 \mathrm{~m})$ in Gothenburg; however their work focusses on CFD simulation and relatively few details of the tests are presented. Beaver and Zseleczky (2009) report a set of tests on an early foiling Moth dinghy at full scale in the USNA Hydromechanics Lab test tank $(116 \mathrm{~m} \times 7.9 \mathrm{~m} \times 4.9 \mathrm{~m})$. These tests focused more on the foiling performance than the displacement mode. In both cases the sizing of the hull relative to the tank was relatively conventional.

In the present study a standard Musto Skiff was tested in the Kelvin Hydrodynamics Laboratory tank. These were the first tests carried out in the present study. In this case the overall size of the hull is much larger relative to the tank than would be considered usual. In order to avoid the need to modify the boat, the towing post was attached via a fitting manufactured to attach to the existing mast step on the boat (with position as in the scale model test). The yaw guide was fitted on the bow, via a post attached to the bowsprit fitting, rather than in the conventional position on the stern; otherwise the test set-up was conventional.

In spite of the length and beam of the boat, the blockage area ratio was still only $0.7 \%$, which is within the range which would be considered acceptable for correction for a conventional ship. However, the tank width is $4.86 \times \mathrm{Bwl}$ (compared to target of 7 ), $1 \times \mathrm{Lwl}$ (compared to target of $2 \times$ ) and tank depth is $0.44 \times \mathrm{Lwl}$ (compared to target of $0.8 \times$ ). Hence the full-scale boat violates all of the guidelines for blockage. The maximum speed is limited in practice to $4.25 \mathrm{~m} / \mathrm{s}$ or just less than 9 knots, by the limitations of the towing carriage and the desire to maintain sub-critical depth Froude numbers. These speeds are typical of upwind sailing in a Musto Skiff in a wide range of conditions and downwind sailing in light to moderate winds. It should be noted that the boat is not planing substantially at these speeds; the Froude number based on volume at $4.25 \mathrm{~m} / \mathrm{s}$ is 1.84 , while the length Froude Number is 0.64 .

The hull was ballasted to the sailing weight of $167.5 \mathrm{~kg}$, and trimmed as described in the previous section so that the transom was just touching the water. No daggerboard was used, and the daggerboard slot was fitted with a divinylcell foam plug. Since it was expected that the open water tests might require the use of a rudder, towing tests were carried out both with and without the rudder fitted in order to allow assessment of the impact of the rudder on resistance. This led to identification of an error in the process. The model had been ballasted to the target weight displacement neglecting the displaced volume of the rudder and daggerboard. In practice it was found that the rudder was found to be positively buoyant, and therefore when fitting the rudder, in order to maintain consistent underwater shape of 
the hull, an additional mass was added to the rudder to correct for the buoyancy and maintain the underwater shape of the hull.

The rudder has a simple geometry: prismatic for the majority of its length with a short tapered section near the tip. The wetted span in the transom-touching condition is $0.85 \mathrm{~m}$, the chord over the $0.615 \mathrm{~m}$ prismatic part is $0.2 \mathrm{~m}$ tapering to $0.16 \mathrm{~m}$ at the tip (neglecting the leading edge profile radius); the maximum thickness is $0.026 \mathrm{~m}$. The rudder is shown in Figure 4.

If the results were being used for accurate assessment of the performance of the hull, then a correction should be made to the assumed weight to allow for the "missing" buoyancy of the appendages. However, the same assumption was made for all tests, so the comparison between results in the baseline condition is still valid. An additional short set of tests was carried out in order to estimate the magnitude of the impact on the resistance of waves in the open water testing, and a further set of tests assessed the impact of varying crew weight on the performance. The boat in the towing condition, the rudder and the towing arrangement are shown in Figure 4.

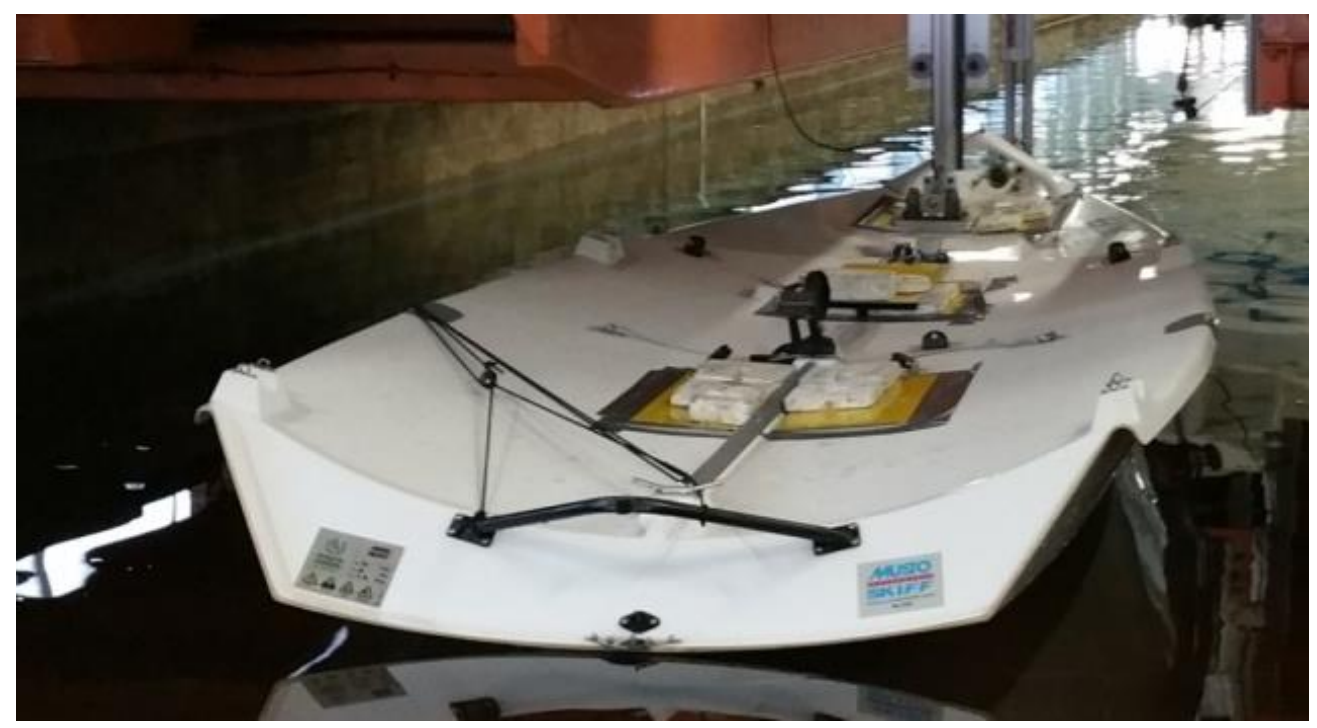

(a) Hull attached to towing carriage (no rudder)

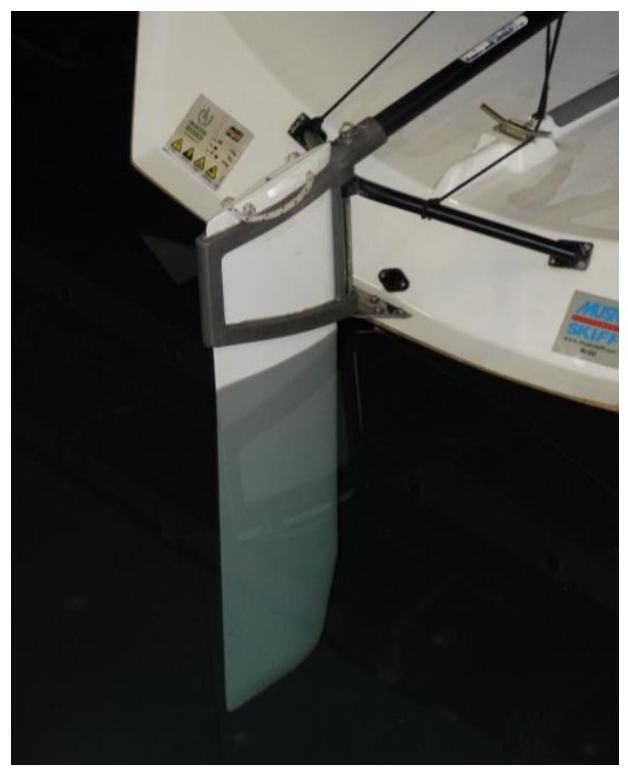

b) Rudder

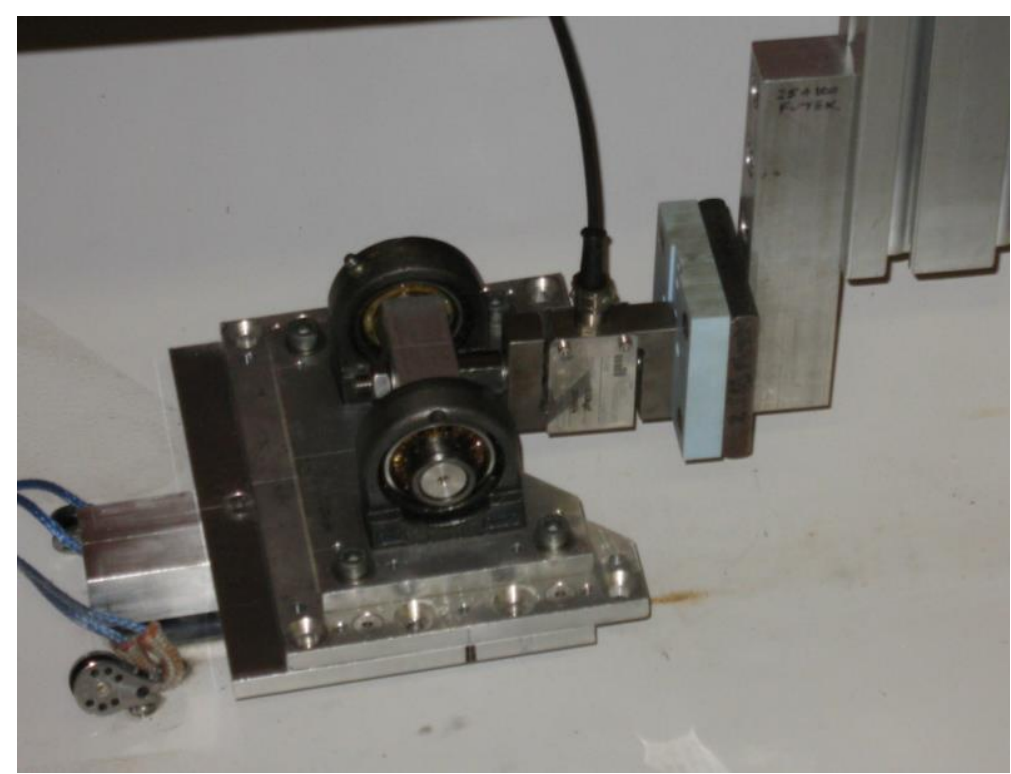

c) Close-up of towing arrangement

Figure 4. Full-scale Musto Skiff in tank 
It should be noted that, in the sailing condition, the trim of the boat will be affected by both the aerodynamic trimming moments (typically bow down) and the longitudinal position of the crew. With a modern high performance dinghy the crew weight makes up more than half of the total weight displacement, and hence a wide range of trim angles can be achieved at any given sailing condition by the crew moving fore and aft; hence in practice the crew will move as the wind rises and falls in order to maintain the trim yielding best speed. In the present study, in order to allow a straightforward comparison between the different cases it is assumed that the crew maintains a longitudinal position varying with speed such that the combination of the trimming moments due to crew position and aerodynamics combine to allow the boat to take up the reference trim at zero speed. The impact on resistance of varying trim is discussed later.

\section{OPEN WATER TOWING TESTS}

The third option for moderate-cost testing, and especially where no tank is available, is to test the hull on open water, by towing a large-scale model (or full-scale dinghy) behind a powerboat. This gives the advantage of no blockage or depth effects if deep water is used, and of course, no tank costs. A number of well-known testing institutions use open-water testing for large scale model testing of maneuvering characteristics of commercial ships, and there is increasing interest in the use of large-scale self-propelled radio controlled models for maneuvering and sea-keeping studies of high-performance powerboats. The challenges of open-water resistance testing are rather different however, since the level of accuracy expected for resistance measurements is generally high, requiring very accurate force and speed measurements, and very calm water.

Carrico (2005) towed a full-scale Laser dinghy on a canal in New Orleans, with the Laser positioned to one side of the powerboat, at speeds of up to eleven knots, measuring speed (using a handheld GPS), resistance (using a load cell), and trim (using an electronic inclinometer). The yaw angle was controlled using two guidelines attached to the towing boat, which allowed the yaw angle to be controlled without the use of a rudder.

Watin (2007) presented a study addressing a number of aspects of the refinement of the design of the well-known Olympic 49er two-man skiff dinghy for the 2008 Beijing Olympics. This study was carried out for Bethwaite Design, following an approach originally developed by Frank Bethwaite (Bethwaite (1993), section 20.1). A substantial part of the study addressed towing of two 49ers from a power boat in Sydney Harbor; the use of two boats allowed comparative studies to be made. The set-up is shown in Figure 5. Both boats were steered, and so the drag values included the drag of the rudder; and the ballast weight included the weight of the crew.

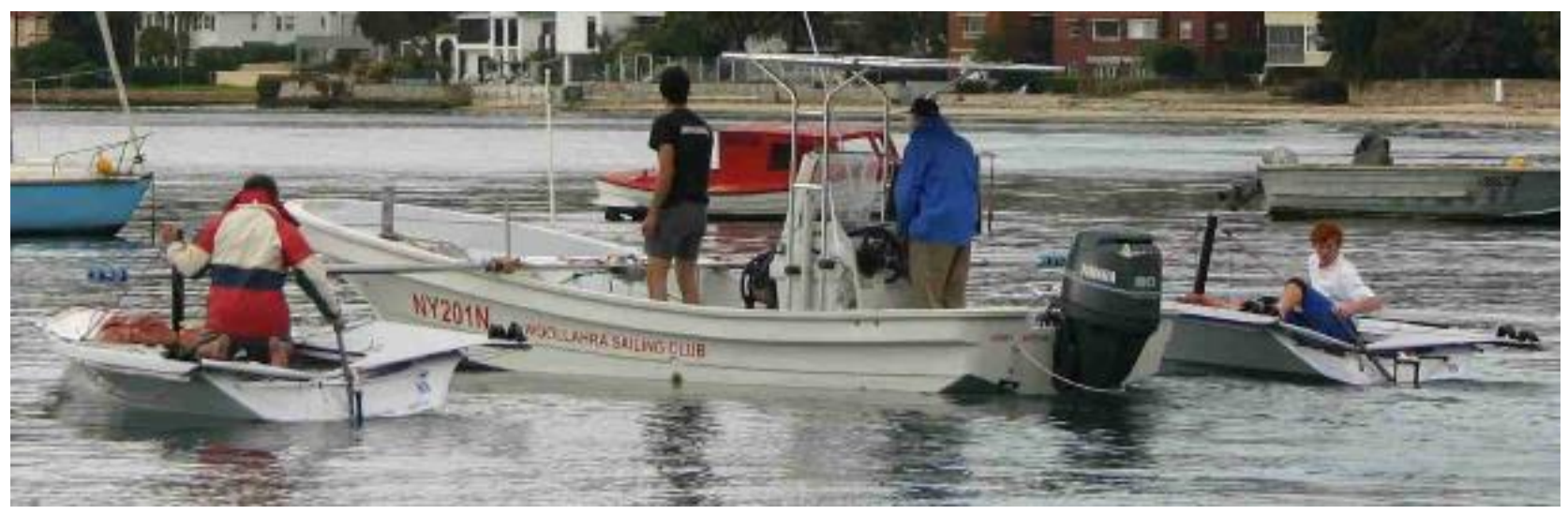

Figure 5. 49er Open Water Towing tests (from Watin (2007)) 
Speed was measured using a GPS, resistance was measured using a load cell, and heel and trim were set visually using marks on the hull.

Following the study of Watin, and in a precursor to the present study, students at the University of Strathclyde towed a Laser and later a Solo dinghy and measured the resistance (see Figure 6). This generated valuable experience in addressing the numerous practical challenges of conducting the tests. The data from the Laser towing was compared to model tests of the Laser from Day and Nixon (2014); the comparison gave sufficient encouragement that the results were reasonable, and could be improved to give worthwhile data.

The towing tests for the present study were carried out at Bardowie Loch located north of Glasgow, Scotland. This small loch (approximately $750 \mathrm{~m} \times 250 \mathrm{~m}$ ) is sheltered in many wind directions, and allowed a test run length of around $500 \mathrm{~m}$. A depth survey of the loch is not available; however it is known that the depth is greater than $6 \mathrm{~m}$ for the majority of loch (since a boat with a $6 \mathrm{~m}$ mast can invert without the mast touching bottom over most of the loch).

The towing boats used were Rigid Inflatable Boats (RIBs) borrowed from the sailing club based at Bardowie Loch. For the first few tests a relatively large RIB was used with a $50 \mathrm{HP}$ outboard engine. It was later found that better results were achieved with a smaller RIB with a 25 HP engine, since the extra power was not needed, the regulation of speed was better, and the boat created less wake.

In the previous open water towing studies at Bardowie, the dinghy had been towed a long distance behind the tow boat rather than to one side as in the tests of Watin. It is relatively difficult to attach a towing "mast" arrangement such as that used by Carrico (2005) or Watin (2007) to a RIB, due to the lack of suitable strong attachment points. The authors were also concerned that the towed dinghy/model would be affected by the bow wave of the towing boat in the side by side arrangement; naturally these waves are largest close to the bow.

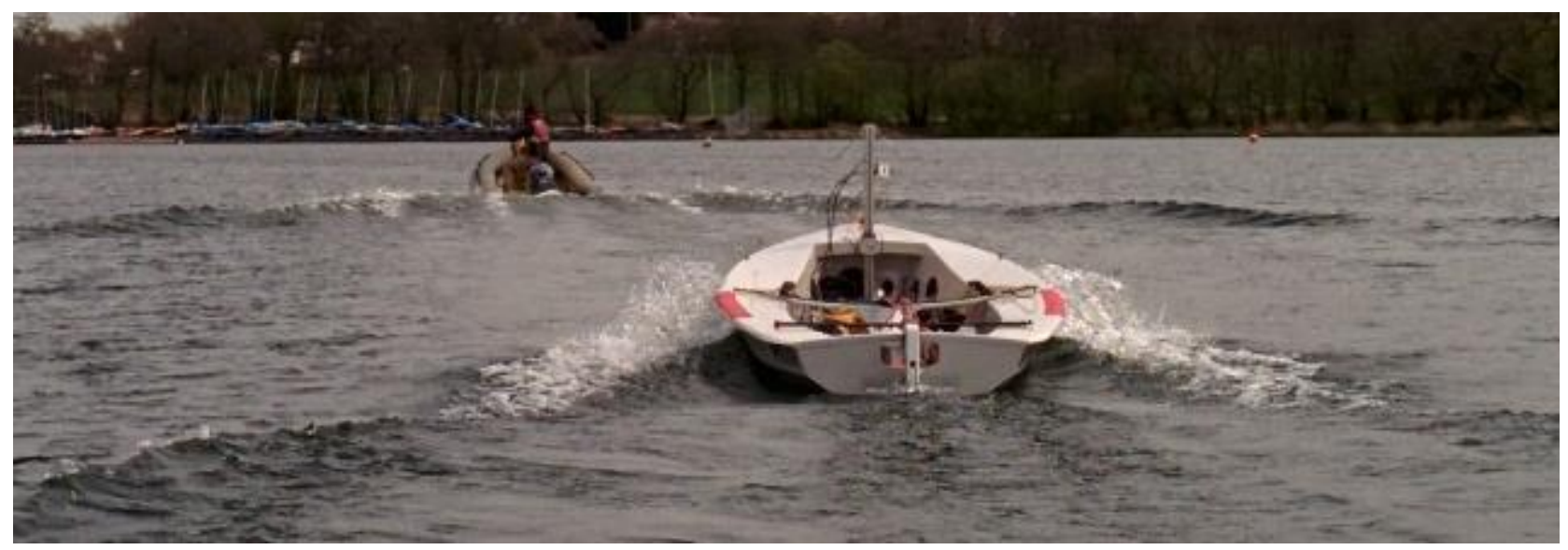

Figure 6. Towing of Solo dinghy in previous tests

Set against this, in a "straight" tow, towing the dinghy behind the towboat leaves the dinghy in the transverse wave pattern of the towboat. This effect may be reduced by towing on a long line; linear thin ship theory suggests that the transverse waves decrease in amplitude with the square root of the distance from the boat generating the waves. A very lightweight dyneema line of approximately $50 \mathrm{~m}$ in length and $0.9 \mathrm{~mm}$ diameter was used to tow the dinghy. This was light enough not to drag in the water due to self-weight over the range of speeds tested. The line was marked so that the length was repeatable between tests. 
The speed was measured using a VBox $3 i$ system. This is a GPS-based system originally intended for measuring speeds of race cars, but increasingly widely adopted for maritime use. The system uses the Doppler shift in the GPS carrier data to measure the speed and heading data, at $100 \mathrm{~Hz}$, with mean accuracy of $0.028 \mathrm{~m} / \mathrm{s}$. The system also contains a data logger which was was used to log analogue data from the load cell via an A/D converter, as well as logging IMU data via a CAN bus interface.

A short mast was located on the dinghy mast step, and supported by rope to the chain plates. An in-house-manufactured 2DOF bending-beam-type load cell was mounted on the front of this mast, which allowed simultaneous measurement of resistance and side force. This was located so that the attachment point of the tow line, at the lower end of the load cell, was situated as close as possible to the vertical position of the tow point in the tank tests in order that the trimming moment was as similar as possible. However it should be noted that the practical consideration of ensuring that the tow line cleared the bow of the boat meant that there was a small difference between the scaled height of the tow points in the two tests. The use of a 2DOF load cell allowed estimation of the towing angle, which could be used to assess when the dinghy was correctly following the towboat. The mast was also used to mount an anemometer and wind vane. The tow line passed through the spinnaker chute mouth to the tow boat.

The VBox was located on the Musto, since it proved more convenient to site the load cell at the dinghy end of the tow-line rather than the towboat end in order to remove the need for any signal cabling between the towboat and dinghy. For this reason, a Velocitek Speedpuck stand-alone GPS speed system was used as a visual guide for the towboat driver. In case of any accidents, the VBox was mounted in a waterproof case along with the battery pack and the strain gauge amplifier (see Figure 7). It was originally intended to include an inclinometer with the system to measure trim, but this proved difficult to power from the battery pack, and hence was not deployed in the end. A 6-DOF IMU (part of the VBox system) was installed, and was used to make a rough estimate of trim, but was found to be not sufficiently accurate to measure the relatively small trim angles found in the tests with an acceptable degree of uncertainty, and hence trim angles from full-scale measurements are not included here. Instrument calibration was checked at the beginning and end of every day. Data was sampled at $100 \mathrm{~Hz}$.

The procedure adopted for the testing was to do pairs of runs in opposite directions upwind and downwind (relative to the very light winds on the testing days) in order to try and eliminate any effects due to atmospheric wind (see Figure 8). For each set of runs, the VBox was started with the dinghy directly behind the towboat, and a timer started to allow individual runs to be easily identified. The towline was paid out slowly until the $50 \mathrm{~m}$ length was all out, and the towboat then accelerated gradually to the target speed. One person drove the towboat monitoring speed and heading, whilst a second person watched the dinghy to ensure that it was following behind the towboat. At the end of the run the towboat would decelerate slowly and the towline would be reeled in so that the dinghy could be turned around and the reverse run started. 


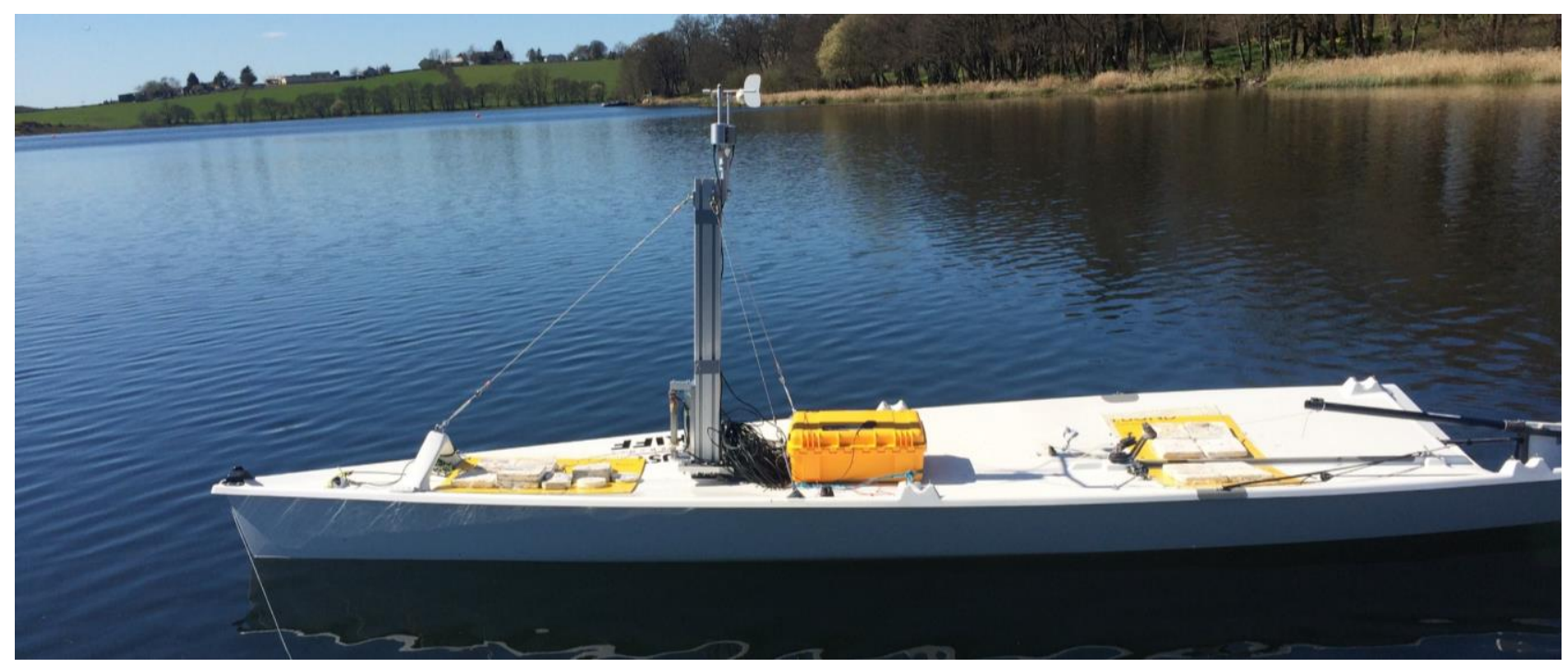

(a) View of hull, mast, and instrumentation

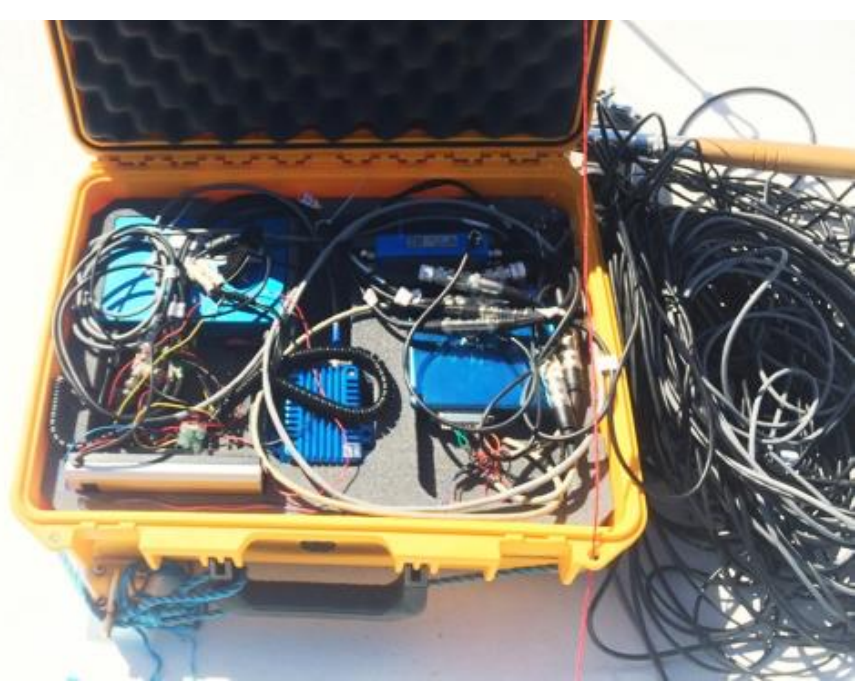

(b) Waterproof case containing Vbox GPS \& data logger and IMU

Figure 7. Instrumentation set-up for open water tests 


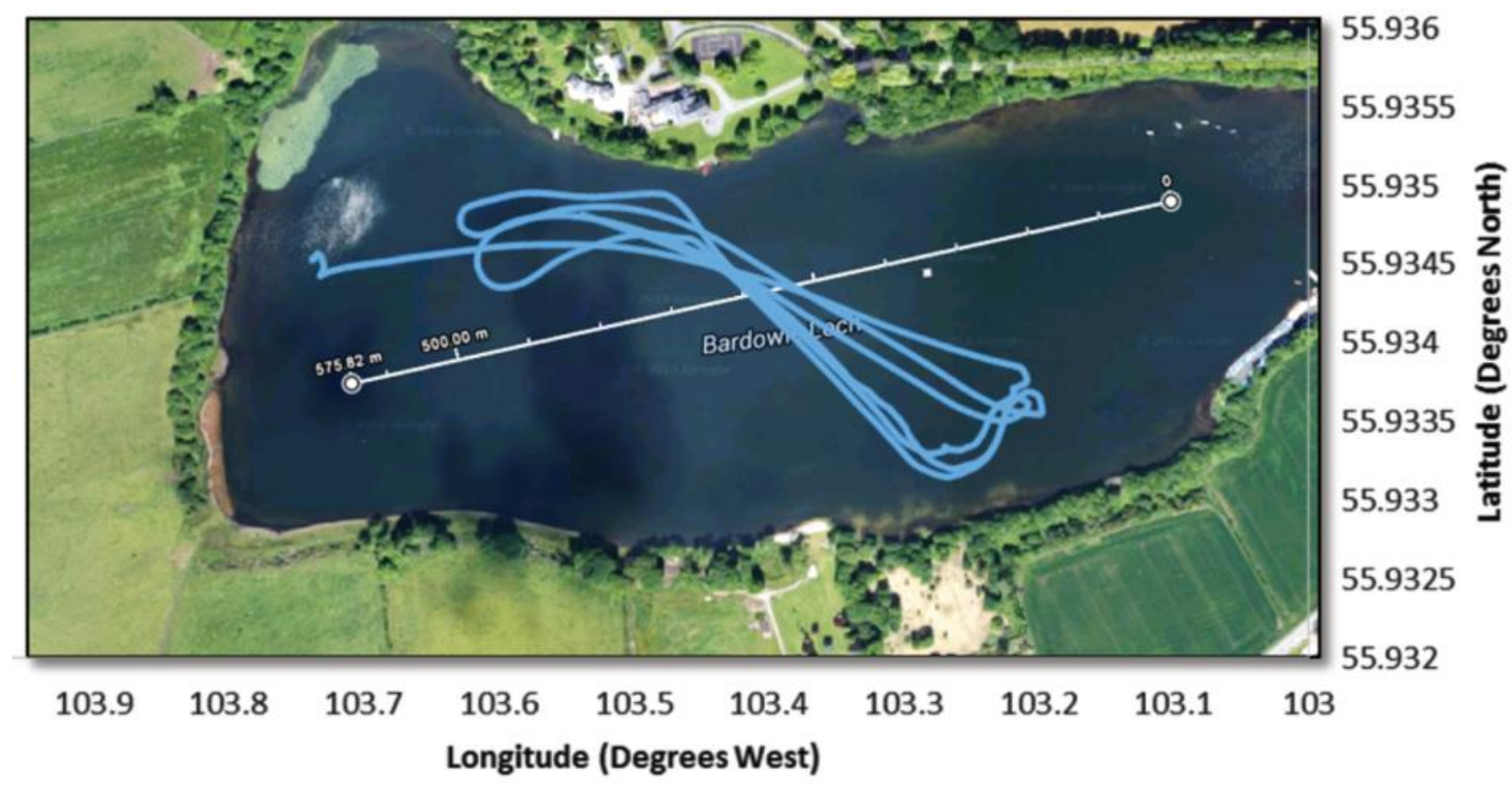

Figure 8. Typical tracks of open-water tests

It was attempted to tow the boat without the rudder in the hope that the hard chine form would prove more directionally stable than the Laser had been. This did not prove to be the case, and without the rudder the boat "fishtailed" from side to side, eventually leading to breakage of the towline. The rudder was then fitted and fixed central with an elastic tie. Some trials were made with a third crew member steering the boat, but it proved difficult to guarantee repeatable heel and trim. However, for future tests this may become necessary.

The ultimate limitation on the speed of the tests proved to be when the results became unreliable due to the increasing wake of the towing boat (see Figure 9). However, it did prove to be possible to replicate the majority of the speed range achieved in the tank tests. 


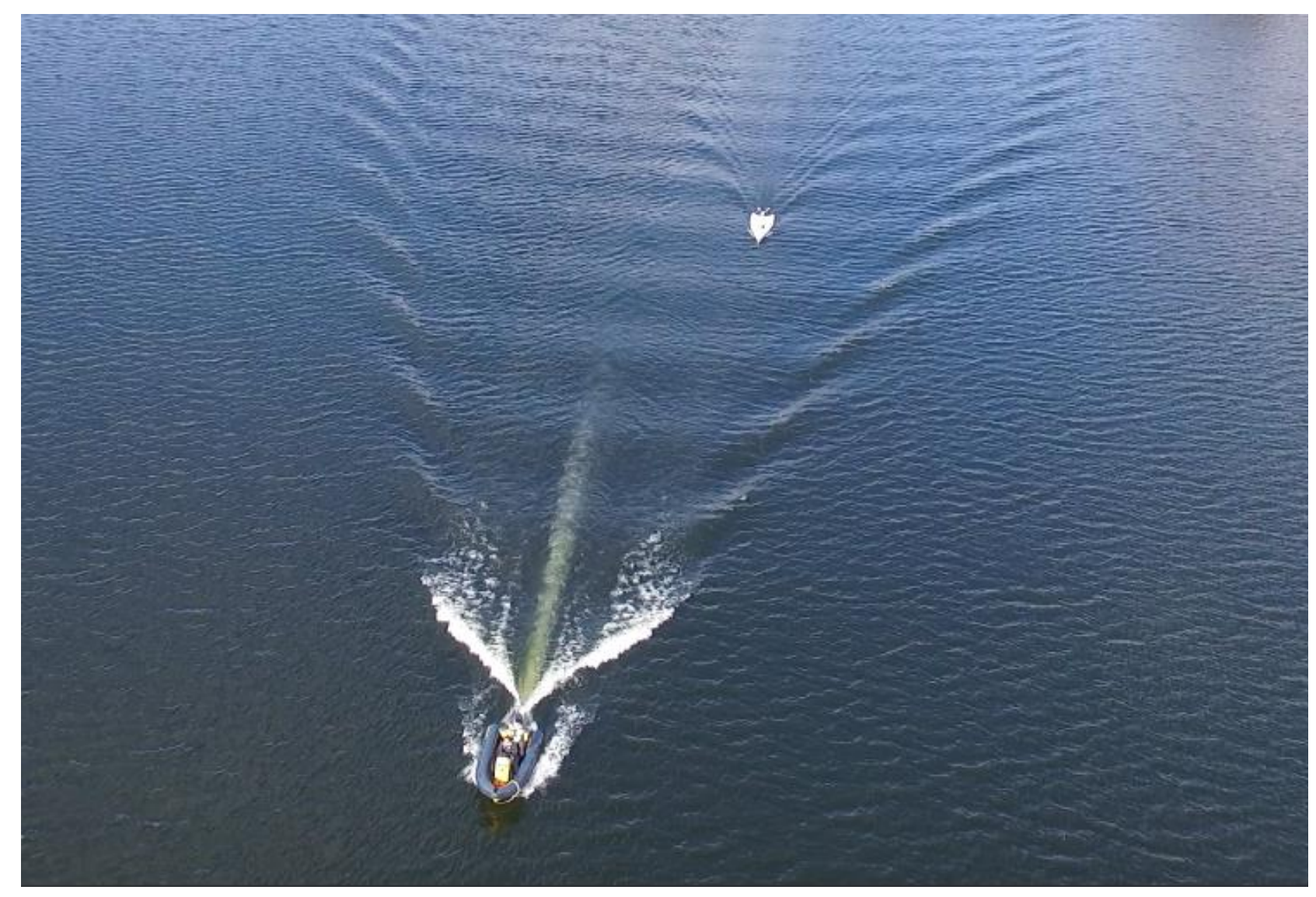

Figure 9. Aerial View of open-water tests

The test conditions for the three cases are summarised in Table 2 below.

\section{Table 2. Test conditions}

$\begin{array}{llll}\text { Property } & \text { Model Scale Test } & \begin{array}{l}\text { Full Scale Tank } \\ \text { test }\end{array} & \begin{array}{l}\text { Full Scale Open } \\ \text { Water }\end{array} \\ \mathrm{Lwl}(\mathrm{m}) & 1.806 & 4.514 & 4.514 \\ \mathrm{Bwl}(\mathrm{m}) & 0.356 & 0.891 & 0.891 \\ \mathrm{~T}(\mathrm{~m}) & 0.058 & 0.146 & 0.146 \\ \text { Width (m) } & 4.572 & 4.572 & >200 \\ \text { Depth (m) } & 2.1 & 2.1 & >6.0 \\ \text { Blockage Area Ratio } & 0.11 \% & 0.65 \% & \mathrm{~N} / \mathrm{A} \\ \text { Maximum speed (m/s) } & 5.67 & 4.25 & 3.94 \\ \text { (Full Scale) } & & & 0.64 \\ \text { Length Froude Number } & 0.64 & 0.64 & \\ \begin{array}{l}4.25 \mathrm{~m} / \mathrm{s} \text { Full scale speed } \\ \text { Depth Froude Number at }\end{array} \text { at } 0.59 & & <0.5 \\ 4.25 \mathrm{~m} / \mathrm{s} \text { Full scale speed } & & 0.94 & \end{array}$




\section{DATA PROCESSING}

\section{Model Scale tank tests}

Model-scale tests were originally conducted over the full speed range achievable in the tank. The data processing for the model scale data followed a standard process for resistance testing. It should be noted that the results from Day et al. (2017) showed a discrepancy with full-scale data at all higher speeds when scaled to full-scale. For the current study, the tests were repeated up to 11 knots full-scale speed, corresponding to Froude Number of 0.85 and volumetric Froude Number of 2.44 , in order to ensure the reliability of the data. In parallel, the original data was completely re-analyzed, and an error related to temperature correction was identified. Once the error was corrected, the repeatability of predictions between the two sets of model-scale tests was typically around $1 \%$. A Prohaska test was carried out for the baseline case which yielded a form factor of 1.032 with a correlation coefficient of $\mathrm{R}^{\wedge} 2=0.993$. This was based on data from model-scale speeds between $0.75-1.3 \mathrm{~m} / \mathrm{s}$; at lower speeds there was evidence of some laminar flow.

The model test data was decomposed in the standard fashion and extrapolated to full-scale using the ITTC 1957 correlation line. The static wetted area for each case was used for extrapolation, since no direct measurement of running wetted area was possible in these tests. However, in the second set of tests an attempt was made to visualize the wetted area using an underwater camera and a grid marked on the hull. An example is shown in Figure 10 for full-scale speeds of $1.5 \mathrm{~m} / \mathrm{s}$ and $4.6 \mathrm{~m} / \mathrm{s}$. It can be seen that the wetted area is not substantially different between the two cases; even though the bow is slightly lifted at the higher speed, the change in wetted area appears relatively minimal. Unfortunately the image quality is not sufficiently good to allow a quantitative analysis of the running wetted area. Figure 10 shows that some spray is present at the higher speed; however the ITTC high speed craft guideline (ITTC, 2017) states "At present there is no accepted method available to account for scale effects in resistance attributable to spray" and hence no corrections were made for spray. 


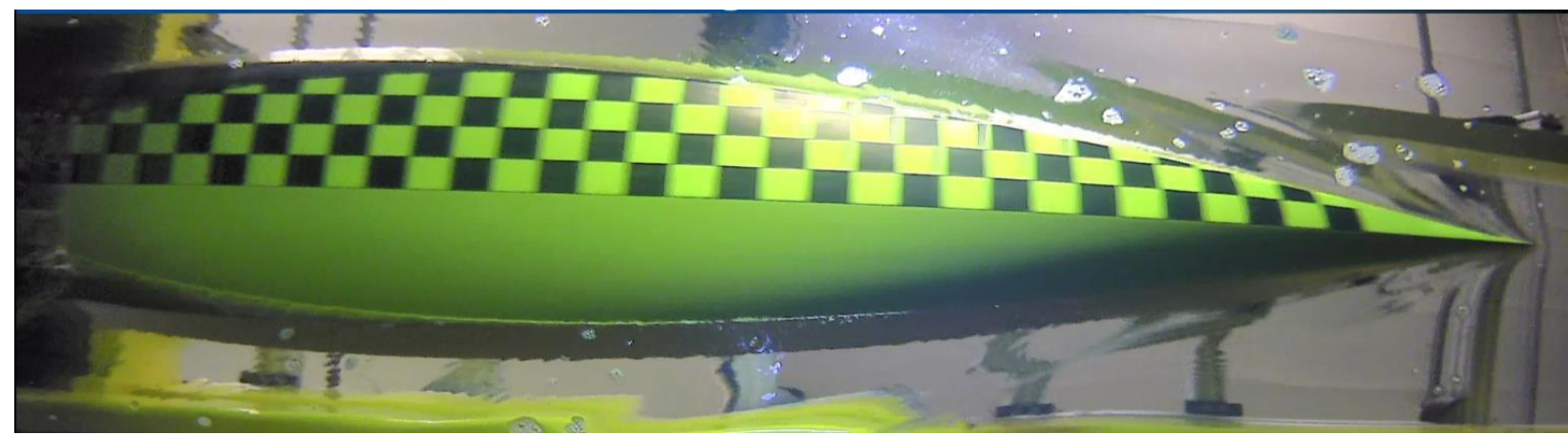

(a) Full-scale speed 3 knots

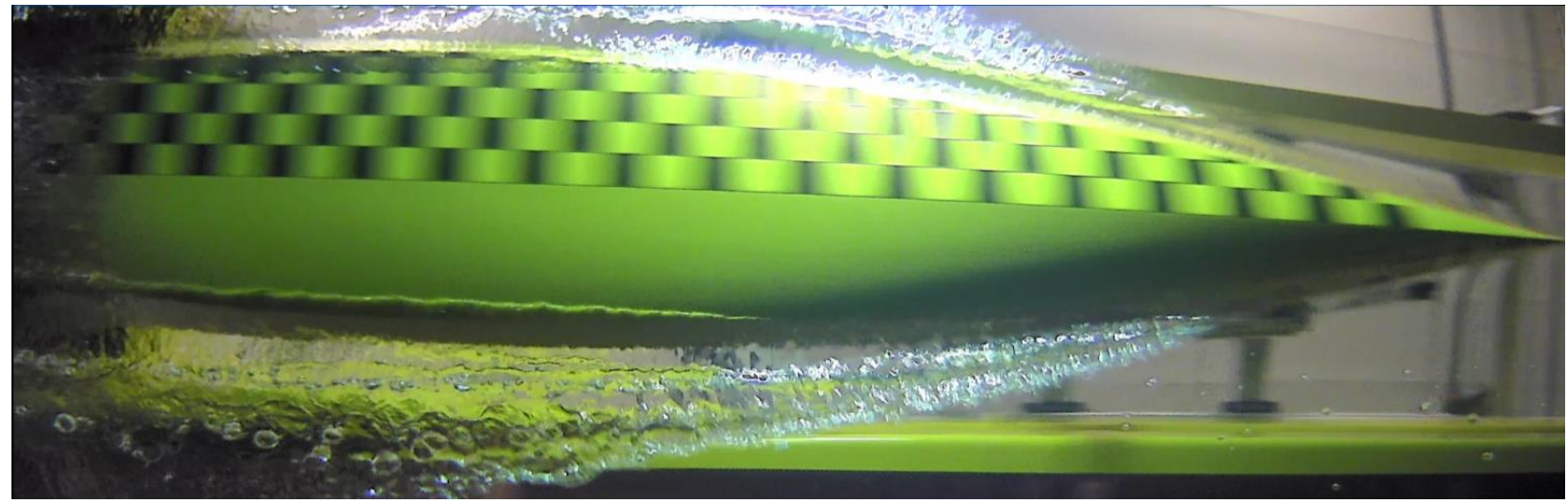

(b) Full-scale speed 9 knots

Figure 10. Underwater view of model-scale hull

Water temperature was corrected to 12.5 degree to match the full-scale tank tests. Repeatability over five repeats yielded a standard deviation of $0.57 \%$ of the mean. The value of 12.5 degrees was chosen (rather than the typical value of 15 degrees) since the water temperature was close to this value in both tank tests and open-water tests; by reducing the magnitude of the temperature correction, the impact of errors resulting from estimation of wetted area would be reduced.

\section{Full Scale tank tests}

The full scale tank results initially require minimal re-processing. The resistance results are adjusted to reflect a constant water temperature of 12.5 degrees (which was similar in the test tank and the loch) and the Tamura blockage correction was initially applied in Day \& Cameron (2017) following the ITTC recommendations. However, the Tamura correction (Tamura (1972)) is based on experiment data with a maximum depth Froude Number of just over 0.6, and was derived using data measured on commercial ship hull forms and a "Wigley" hull - which are very different from the hull tested in the present study. This depth Froude Number corresponds to a speed of around $2.7 \mathrm{~m} / \mathrm{s}$ in the present study. As a result, the correction cannot be guaranteed to be reliable at the depth Froude numbers found for the higher speeds in the test tank in the present study. Results here are therefore initially presented with no blockage or depth corrections (in contrast to the results of Day and Cameron (2017)).

As an indication of the repeatability of the results, a set of five repeats was carried out at a speed of $3.342 \mathrm{~m} / \mathrm{s}$. The standard deviation of the resistance over the five repeats was found to be $0.33 \%$ of the mean value. 


\section{Open-water tests}

The data processing was substantially more complex for the open water tests than for the tank tests. A number of practical issues had to be resolved. Analysis of the data from the anemometer and the wind vane suggested that the measured wind data was not reliable and accurate. It was subsequently discovered that the output voltage from the battery pack was reducing during the day, which affected the data from the (entirely analogue) anemometer and wind vane system. Hence it was not possible to make the intended correction for windage. It thus became very important to average upwind and downwind runs in order to cancel any effect of the windage, even though the prevalent winds were light over the testing period. Whilst the water in the loch is essentially still other than due to winddriven currents, this averaging also allowed the effect of any small surface currents to be reduced.

It is inevitable that the data for open-water tests is noisier and more scattered than data from tank tests, and hence requires careful quality control. The key challenge in the data analysis was to find segments of data for the two directions for which the speed matched sufficiently well. The data was selected according to two objective and quantitative criteria. After some experimentation the first criterion adopted for acceptance of the data segments was that the average speeds for the upwind and downwind segments of data should be different by less than 0.2 knots. This criterion removed the majority of the outlier points, and also removed several points which fitted the general trend. A second criterion was set to remove points which displayed a substantial discrepancy in drag (here set at $15 \mathrm{~N}$ ) between the two directions; this led to the removal of two further points. A sample segment of the time history is shown in Figure 11a. The lower trace shows speed (in $\mathrm{km} / \mathrm{h}$ ) whilst the upper trace is the amplified voltage output from the load cell. The cursors indicate the section chosen for analysis - in this case around $35 \mathrm{~s}$ of data. A plot of the processed data obtained is shown in Figure 11b, showing the points retained and discarded, along with a sixth order polynomial fit of the data retained.

\section{Correction for rudder}

In order to compare the three sets of tests, it is necessary to make a correction for the rudder, since the model scale tests were only conducted without the rudder and the open water tests only conducted with the rudder. Figure 12 shows the effect of the rudder on the total resistance. Here the resistance curves have each been interpolated onto the same speed steps using a cubic spline, before subtracting to find the difference. Whilst the effect is small as a proportion of the hull resistance, the trend displays some unexpected behavior. At speeds of less than $3.0 \mathrm{~m} / \mathrm{s}$, the delta due to the rudder increases roughly as might be expected; however, there is a sudden drop in the region between 3.0 and $3.5 \mathrm{~m} / \mathrm{s}$. Some insight into this phenomenon may be gained by examining the trends in the trim of the boat, shown in Figure 13. It can be seen that the trim angles are almost identical up to $3.0 \mathrm{~m} / \mathrm{s}$ but start to diverge around $3.0 \mathrm{~m} / \mathrm{s}$. The boat starts to adopt bow-up trim around $2.75 \mathrm{~m} / \mathrm{s}$, and exhibits around one degree of bow-up trim at around $3.25 \mathrm{~m} / \mathrm{s}$. The trim angles start to diverge at that point, along with the sinkage, and it is assumed that it is this effect, possibly combined with the impact of the rudder on the wave pattern, which contributed to the complex behavior in resistance. Other studies of high performance sailing vessels have yielded observations of complex interaction between rudder and hull resistance (Claughton (2019)). The delta shown in Figure 12 was therefore used to correct the open water data to remove the effect of the rudder on the resistance to allow direct comparison between the three cases. 


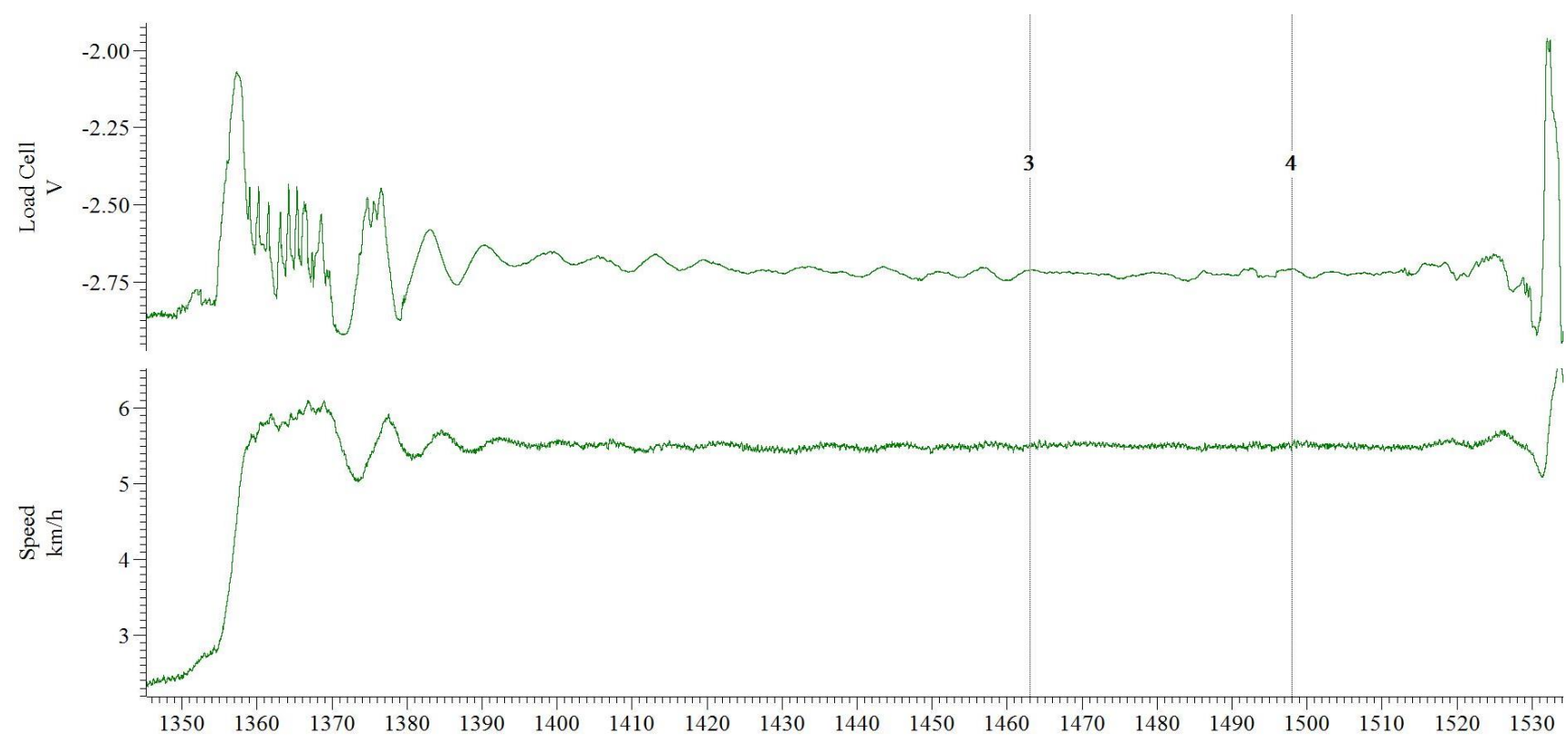

a) Sample time history of open water data

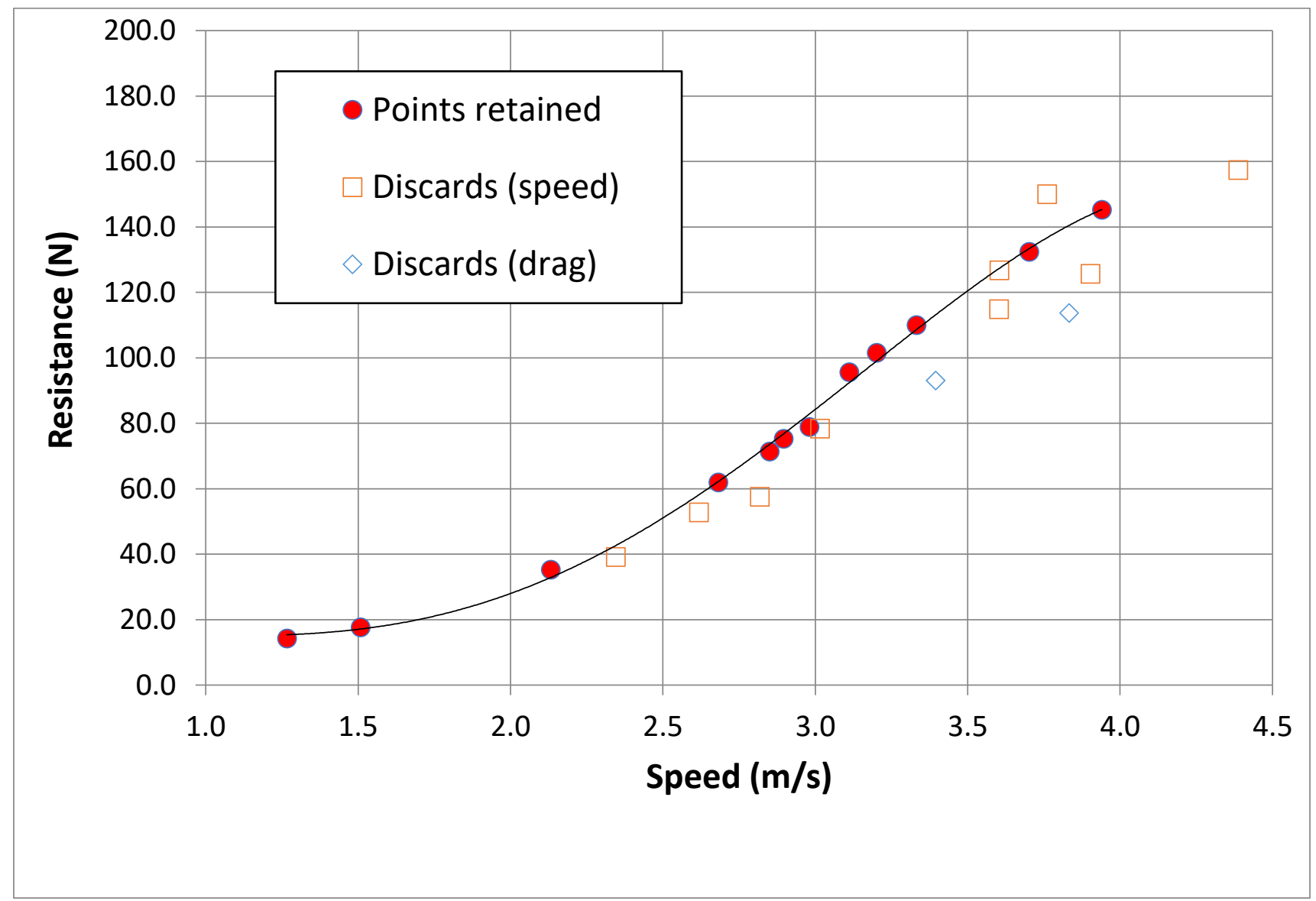

(b) Selected processed points from open water testing

Figure 11. Open water test data 


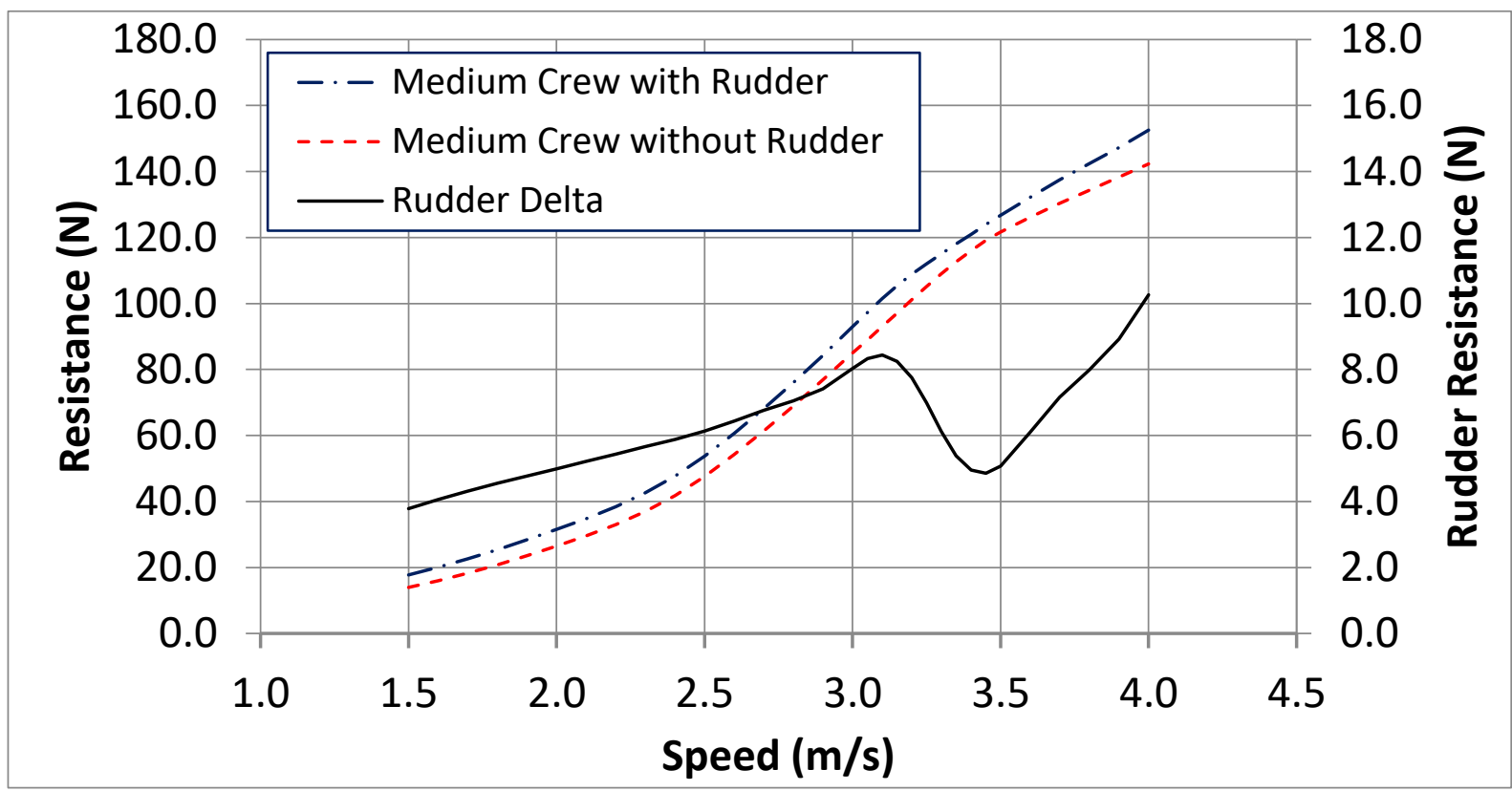

Figure 12. Effect of Rudder on resistance: full-scale tank tests

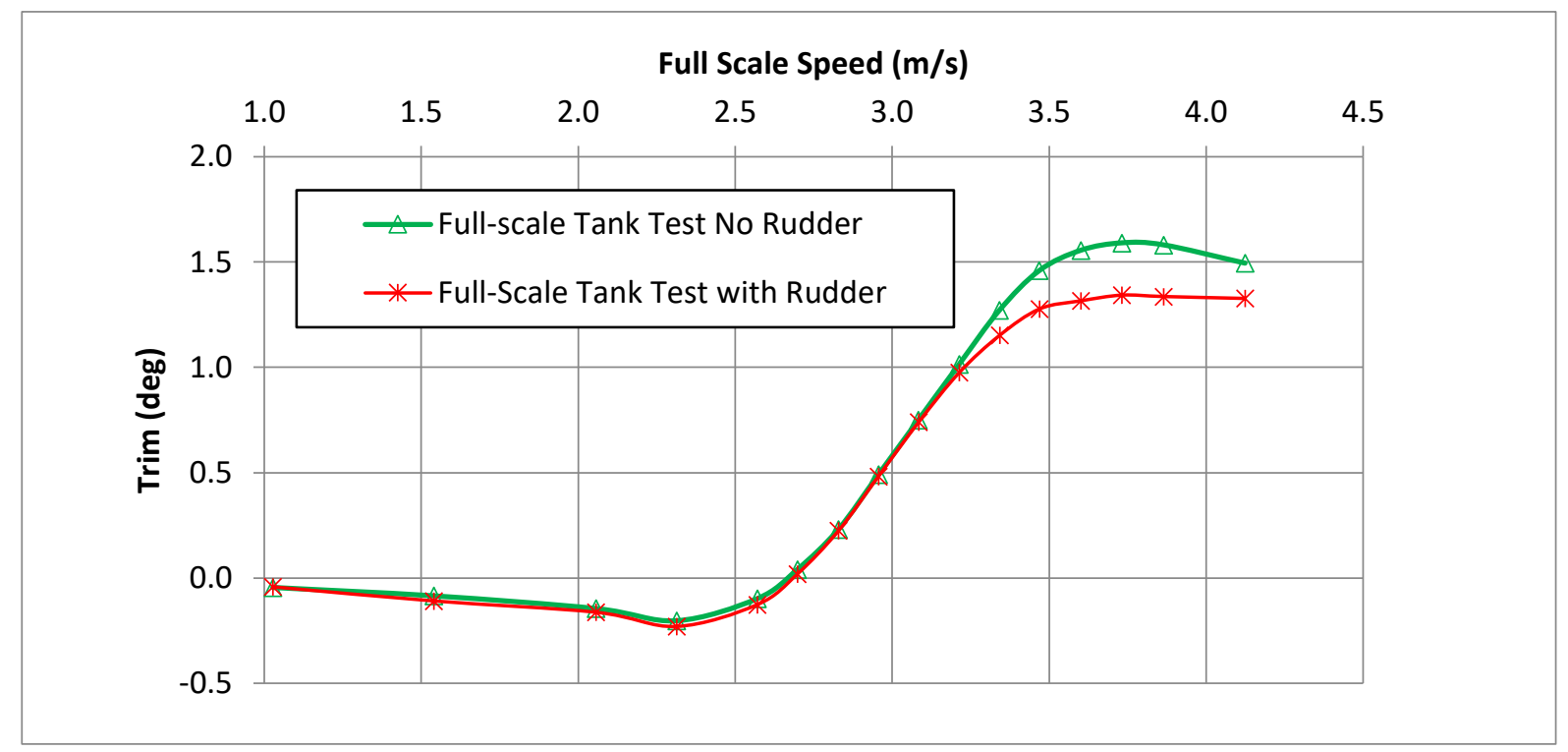

Figure 13. Effect of Rudder on trim: full-scale tank tests

\section{RESULTS - COMPARISON OF RESISTANCE DATA FROM THREE APPROACHES}

\section{Comparison of open-water tests and tank tests}

Figure 14 shows the comparison of the data from the three sets of tests. It can be seen that all three sets of data match well up to around $2.75 \mathrm{~m} / \mathrm{s}$, corresponding to a Froude Number just over 0.4. For the higher speeds, the open water data (corrected for the rudder) still matches quite well with the model test data, whilst the full-scale tank test data is rather higher than both. The average absolute error between model scale tank test and the polynomial fit for the open water data (after correction for the rudder) is just under $4 \%$ in the range between $1.5-4.0 \mathrm{~m} / \mathrm{s}$; this improves to $3.4 \%$ in the range $2.75-4.00 \mathrm{~m} / \mathrm{s}$. These errors can be compared to the average error between the two sets of model test data (the original tests and the retests) of around $1 \%$. 


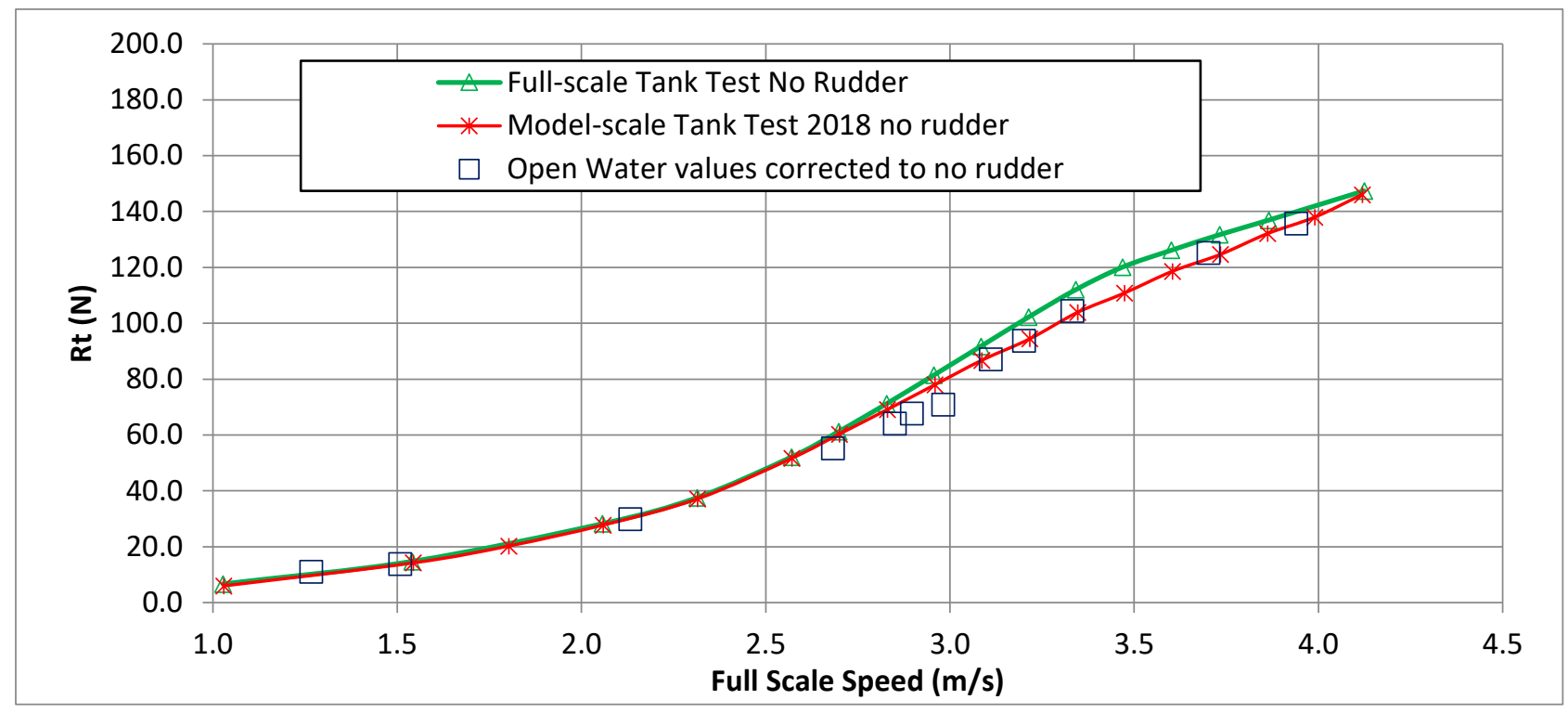

Figure 14. Comparison of resistance: all tests (open-water data corrected for rudder)

The model test data agrees well with the full-scale tank data at speeds of less than $2.75 \mathrm{~m} / \mathrm{s}$. There is some evidence that the model-scale resistance is very slightly less than the fullscale data, which may be due to the effect of increased impact of laminar flow in the model tests. However the comparison of results at low speeds between the two test campaigns suggest that the lack of turbulence stimulation on the model hull has not led to significant errors in the data.

In comparison, the discrepancy between the full-scale tank test data and the other two data sets is much greater in the region from $2.75-4.0 \mathrm{~m} / \mathrm{s}$, with an average discrepancy in this region of $5.5 \%$, and a systematic bias towards higher resistance in the full-scale tank tests. The hull geometry is of course the same between the open-water tests and the full-scale tank tests, so this cannot explain the divergence of the full-scale tank data from the other two data sets; similarly, the discrepancy cannot be attributed to the rudder correction, since both tank data sets exclude the rudder. The effect of any small waves in the open water tests would be expected to increase the resistance (as shown later in Figure 16), which suggests that these effects are not the cause.

Two issue are suggested which may have contributed to the higher resistance for the fullscale tank tests. The first is the effect of the finite width and depth of the tank. At $3.5 \mathrm{~m} / \mathrm{s}$, where the discrepancy is greatest, the depth Froude number for the full-scale tank test is 0.77 . This is well beyond the range of the Tamura correction discussed earlier, and may be expected to cause an increase in wave-pattern resistance, and a corresponding change in trim and sinkage.

\section{Correction for tank restrictions}

In order to investigate these phenomena further, an attempt was made to make a correction to the full-scale tank test results to remove some of the effects due to the restricted width and depth on the wave resistance by using a relatively simple linear "thin-ship" wave resistance code. It should be noted that this linearised code cannot predict the impact of trim or sinkage on the resistance. Whilst the thin ship theory may not necessarily be expected to predict the wave resistance with great accuracy for a hull of this form, it may be reasonable to use the theory to estimate the relative value of the wave resistance in the tank compared to the value in unrestricted water. The wave pattern resistance of the Musto hull was calculated using the code of Day and Doctors (2001)) for both unrestricted waters and for a channel with the width and depth equal to that of the towing tank. The code uses a "virtual 
appendage" approach for addressing transom sterns. This code is similar in underlying theory and function to Lazauskas' "Michlet" code as used by Radojcic and Bowles (2010) in their review of shallow water effects, and similar in theory to the approach of Lunde (1951) suggested as a possible strategy in the ITTC High Speed Marine Vehicle guideline (2017). The method computes the resistance very rapidly: prediction of resistance for 15 points over the speed range deployed here takes less than a half a second on a typical desktop PC.

The ratio of the predicted wave resistance coefficients at each speed for these two cases was calculated and used to correct the wave resistance coefficient derived from the fullscale tank test. The total resistance was then reconstructed using this corrected value. The equivalent correction factor was also calculated for the model scale tests. The results are shown in Figure 15. The model scale results show a correction factor very close to unity over the whole range; in contrast the full-scale results suggest a substantial wave-resistance correction factor, peaking over 1.12. Once this factor is applied to the derived wave resistance it can be seen that the majority of the discrepancy between the two sets of tank results is removed quite successfully: following the correction, the full-scale tank results agree satisfactorily with the model-scale results over the majority of the speed range, with the exception of the highest speed, for which the depth Froude number is $>0.9$.

\section{Comparison of Trim and Sinkage}

The second effect relates to trim. The longitudinal position of the towing point was set to be the same in all three cases, but inevitably there were minor differences in the details of the towing arrangement between the model and the full-scale hull, including the scaled height of the tow point relative to the baseline. The change in the relative position of the resistance force due to the change in the breakdown of resistance between frictional and wave effects may also affect the trim of the boat. The trim is also likely to be affected by changes in the wave pattern caused by depth effects, and, as discussed above, this effect cannot be corrected by the thin ship approach adopted. A comparison of the trim and sinkage in the model-scale and full-scale tank tests is shown in Figure 16.

It can be seen the sinkage is quite consistent between the two data sets; there are some slight discrepancies in sinkage at the lower speed range, but these occur when the measured sinkage is small and could be due to a combination of measurement uncertainty and/or some "stiction" in the heave post exacerbated by the relatively light weight model of the model. The running trim values are very close up to a full-scale speed of around $2.75 \mathrm{~m} / \mathrm{s}$. However, for speeds in the range between $2.75-4.0 \mathrm{~m} / \mathrm{s}$ the values of trim diverge, with the model exhibiting less bow-up (positive) dynamic trim, while at the highest speeds $(>4.0 \mathrm{~m} / \mathrm{s})$, the model-scale dynamic trim is once again similar to the full-scale value and the resistance curves converge. It is worth noting that the discrepancies in trim occur in the same speed range as the discrepancies in resistance (see Figure 14), so it is reasonable to assume that finite depth effects are at least partly responsible for the discrepancy in trim.

\section{Further issues}

In relation to the differences between the open water tests and the model-scale tests, it is natural to assume that these result from scatter in the open water data caused by the challenges of measurement in an uncontrolled environment, and issues associated with correction for rudder effects, the wake of the towing boat, and small discrepancies in trim caused by differences in the towing arrangement. The use of a constant length tow-line inevitably meant that at some speeds the towed hull was sitting on the back of a stern wave whilst at other speeds it was on the face of a wave; this may explain some of the variation. In future an attempt could be made to vary the tow-line length to reduce this effect; however reducing the wave wake from the towing boat might well be more effective. 


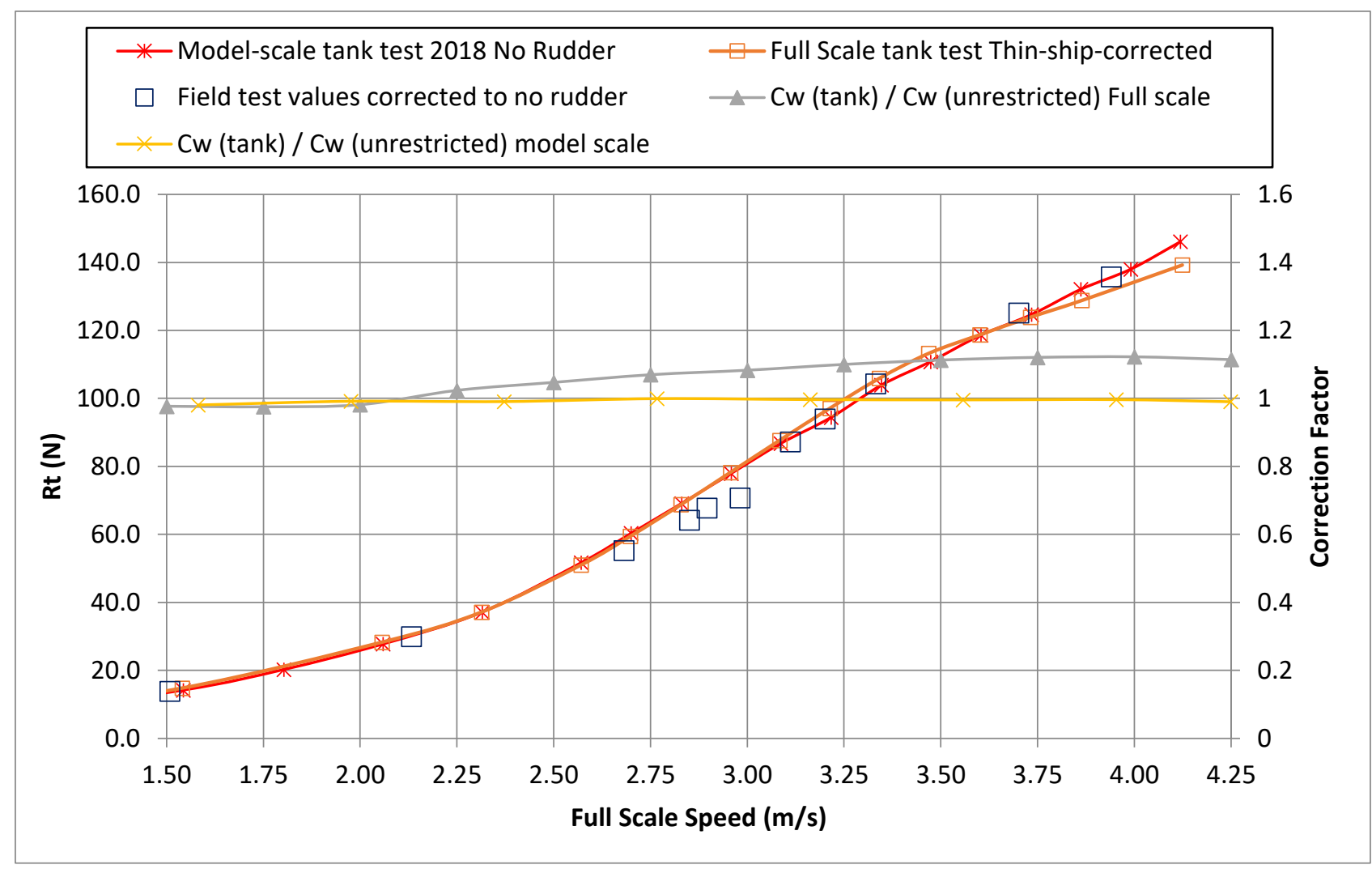

Figure 15. Comparison of resistance: all tests

(full-scale tank data corrected via Thin-ship theory)

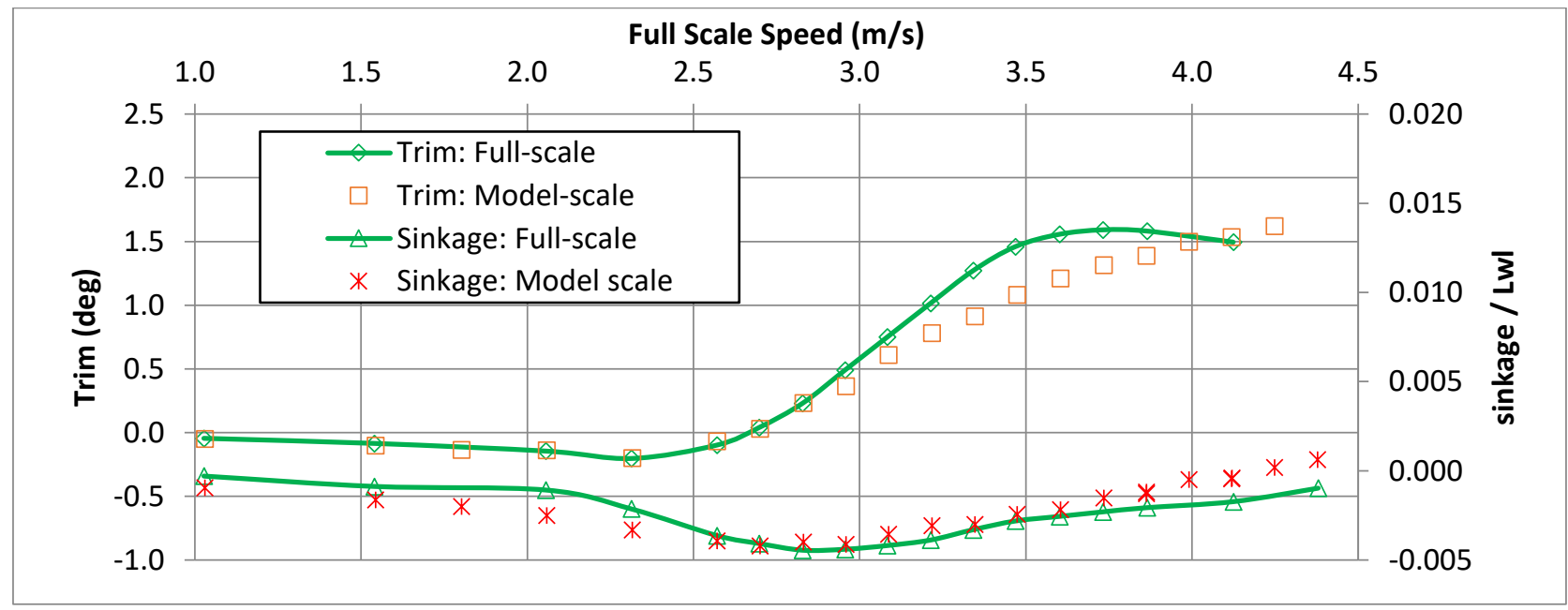

Figure 16. Tank Tests: Trim and sinkage from full scale and model scale tank tests

It is also possible that differences in geometry between the model and the full-scale hull contribute to these small differences. The model was built from a lines plan supplied by the builder. This plan probably relates to the prototype boat, which was built in plywood. The model was very similar, but not completely identical, to the full-scale boat. In some areas (e.g. the sheer-line \& the transom profile) the differences were above both static and running waterlines, and thus had little or no impact on the hydrodynamics. Other modifications, including the incorporation of a small radius on the chine line of the production boat, which was sharp in the model, and a minor change to the forefoot profile, may have been made to ease challenges associated with molding the production boat. The sharpness of chines is 
known to have an effect on resistance of skiff hulls: Watin (2007) suggests that sharpening chines on a $49 \mathrm{er}$ hull could reduce resistance by $15 \%$ over a range of speeds. This emphasizes the importance of correct modelling of small details of geometry.

Nonetheless the results show that it is possible to get results from open water towing tests which may be meaningfully compared to model-scale tank testing when tests are carried out and analyzed with care. Improvements could certainly be made in test procedure, and the successful deployment of an anemometer and IMU could certainly help to improve data quality. Perhaps the biggest improvement could be achieved by adopting an improved strategy for choosing the speed of the towing boat in order to allow more pairs of data segments which can be matched with sufficient accuracy between upwind and downwind runs. In addition the choice of a more suitable tow-boat with reduced wave wake would allow better results at higher speeds.

In contrast, testing the full-scale boat in a moderate scale tank appears rather more problematic when depth Froude numbers are high. However the use of a simple thin-ship theory to predict correction factors for the wave resistance yields satisfactory agreement with the model-scale results in the present case at depth Froude numbers up to around 0.9.

\section{EFFECT OF WAVES, DISPLACEMENT AND TRIM ON RESISTANCE}

In addition to the baseline tests described above, a series of additional tests were carried out in the test tank at both full scale and model scale.

\section{Effect of waves}

A further set of tests with the full-scale boat examined the effects of small waves on the resistance. The aim was to estimate the magnitude of any error due to small waves in the open water testing. The waves had amplitude of $20 \mathrm{~mm}$ and wavelengths of $1.0 \mathrm{~m}, 1.5 \mathrm{~m}$ and $2.0 \mathrm{~m}$ for Waves \#1, \#2, and \#3 respectively. The results can be seen in Figure 17. The shorter wavelength waves have the larger effect with mean deltas over the speed range of $11 \% / 7 \% / 4 \%$ respectively. In addition to indicating the impact of even very small waves on hull resistance when sailing, this plot emphasizes the importance of measuring on a calm day in open water testing, and also indicates the challenges which may be associated with the use of a towed probe to stimulate turbulence in a tank test.

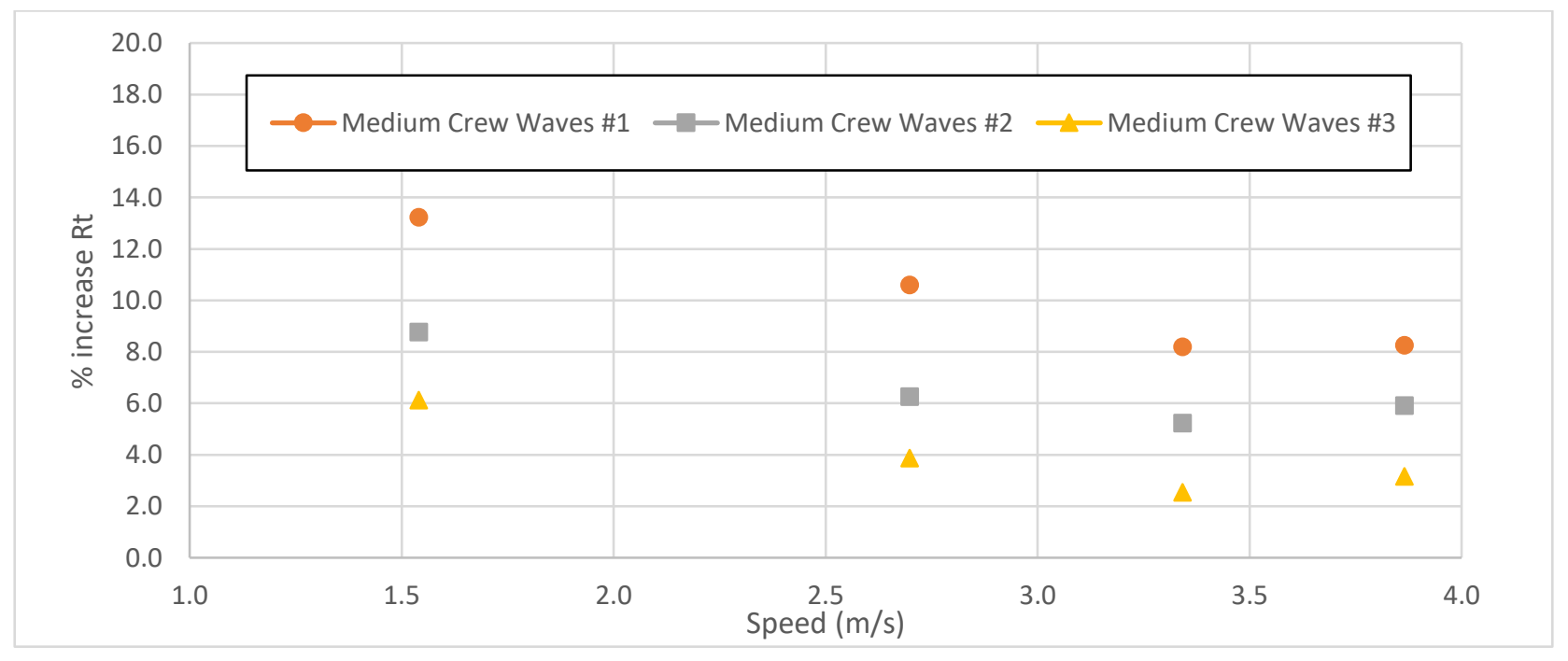

Figure 17. Full scale tank tests: Effect of waves 


\section{Effect of Crew Weight}

In the final set of tests for the full-scale boat in the tank, the impact of crew weight on the resistance was studied. In these tests, the total displacement of the boat was varied by $+/-$ $10 \mathrm{~kg}$ to simulate the effect of a $70 \mathrm{~kg}$ and $90 \mathrm{~kg}$ crew on the upright resistance. In each case, the trim of the boat was adjusted so that the transom was just touching the water. Results are shown in Figure 18.

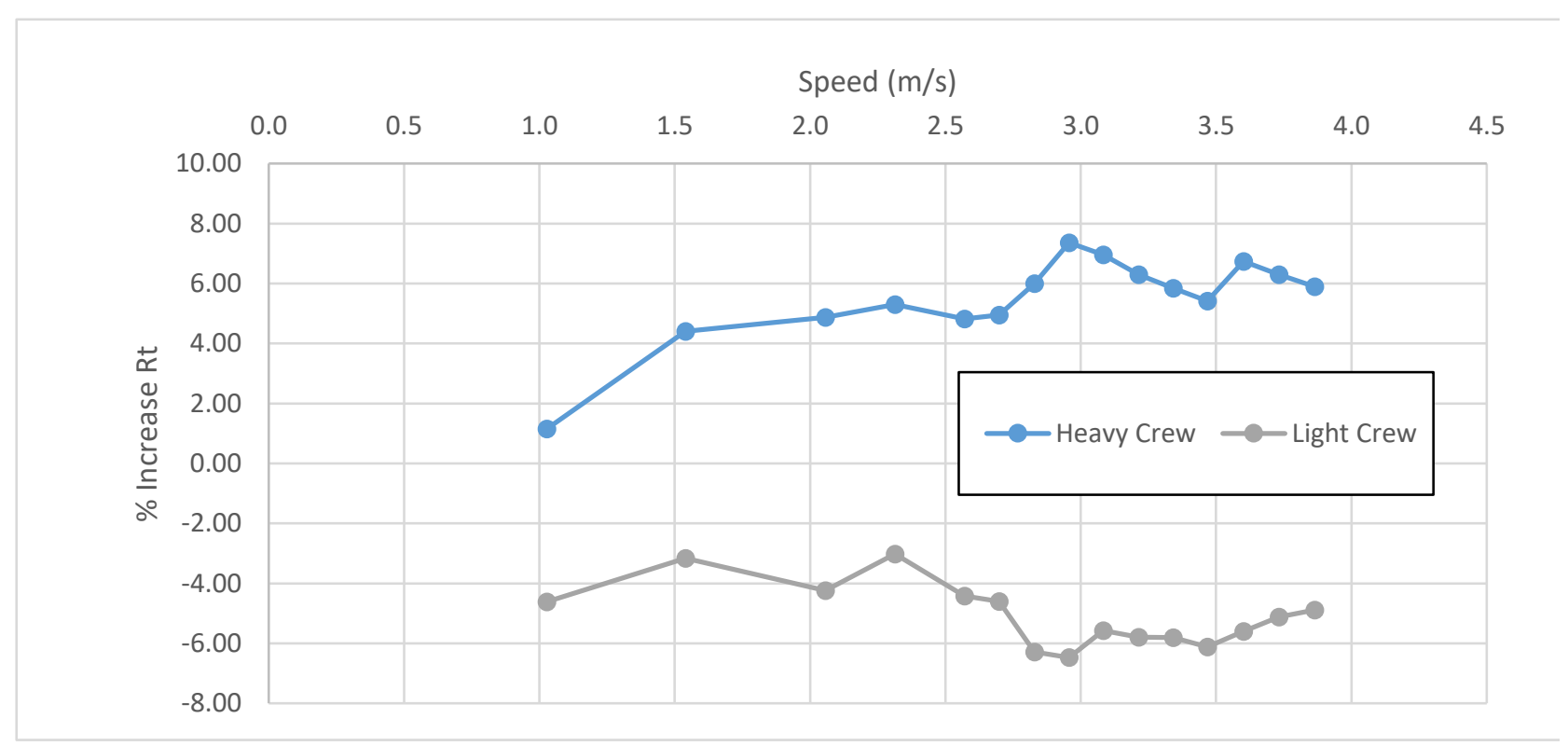

Figure 18. Full scale tank tests: Effect of crew weight

As expected, the lighter displacement yields lower resistance over the speed range, whilst heavier displacement gives greater resistance over the range. The mean changes in upright resistance for $-/+10 \mathrm{~kg}$ are $-5.1 \% /+5.8 \%$ over the full-scale speed range from $4.0-9.0$ knots. These values are broadly similar to the corresponding values for the Laser dinghy over the same speed range $(-5.4 \% /+4.5 \%)$ in the study by Day \& Nixon (2014) in spite of the pronounced difference in hull form between the Musto Skiff and the Laser. Naturally the variation in weight also impacts the available righting moment; hence it is not obvious from this plot which weight gives the best speed around a course in a given wind speed; to determine this a more detailed VPP study including the effect of crew weight, such as that of Day (2017), would be required.

\section{Effect of Trim}

Hard-chine hulls such as these are known to be sensitive to trim, especially at low speed. In order to explore this phenomenon, the model-scale hull was re-ballasted to give a "chinelevel" condition which is more typical of upwind sailing trim in moderate conditions for the Musto Skiff than the "transom touching" condition. Figure 19 shows the comparison between the conditions scaled to full-scale for the model-scale tests. At the highest speed in the 2018 tests, the volumetric Froude Number is 2.44.

It can be seen from the figure that the "chine-level" condition yields substantially more resistance at lower speeds due to the immersed transom; in the speed range between 3.5$4.5 \mathrm{~m} / \mathrm{s}$ there is little to choose between the two trims, but the chine-level condition gives 
slightly better performance at the higher speeds. It may also be expected that the chinelevel condition will also give slightly better directional stability, and certainly less risk of nosediving in waves, although these tests provide no information on these phenomena.

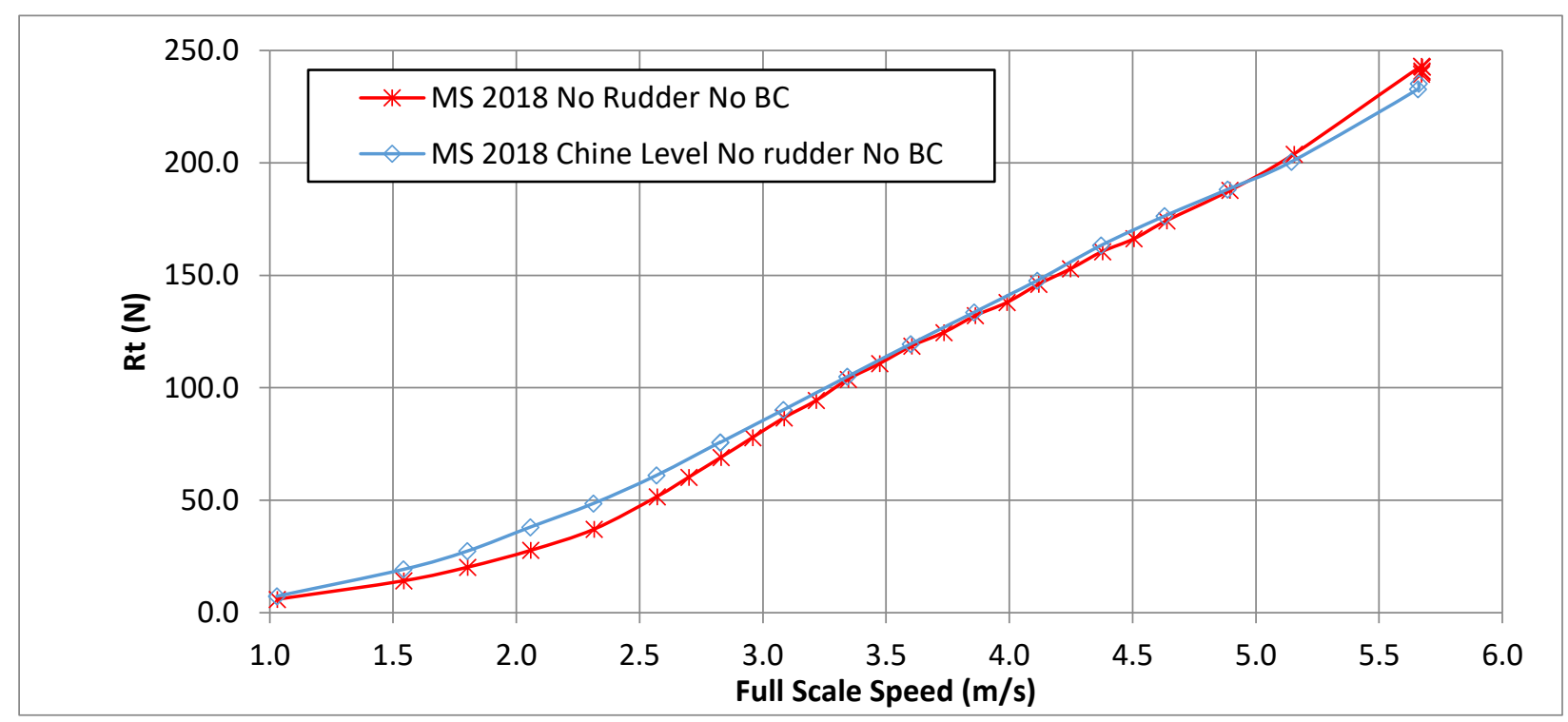

Figure 19. Effect of static trim

\section{Comparison with approximate numerical predictions}

Many velocity prediction programs used for the design of high-performance yachts are based on regression methods for prediction of resistance. it is therefore of interest to compare the tank-test results with those which may be obtained from well-known approximate methods. For the plots presented here, all the model scale results (scaled to full scale) were used, including the higher speed runs.

One of the most widely used approaches is that derived from the Delft series, given in Keuning \& Katgert (2008)). This was based on regression of results from 55 models; all of which were round bilge yacht forms, in contrast with the hard chine skiff form tested here.

In the "transom-touching" condition, the hull parameters do not all fall within the range of parameters tested in the Delft series. In particular the LCB at $49.5 \%$ aft of FP is further forward than any of the Delft series, and the ratio of LCBfpp/LCFfpp at 0.865 is extremely low compared to any of the Delft hulls. It is therefore no surprise (and no criticism of the Delft series) that the Delft regression equation fails to predict even the trends of the resistance of this skiff hull with any degree of accuracy, as shown in Figure 20. The challenges of predicting resistance of such hull-forms has been the driver behind studies such as the SYRF "Wide - Light Project" (Claughton (2015)).

A second attempt was made to predict the resistance using Savitsky's approach for hardchine planing hulls for both pre-planing and planing conditions as implemented in the MaxSurf Resistance sofware. (Savitsky (1976)), based on a deadrise angle at 50\% Lwl of 16 degrees. It can be seen from Figure 20 that the pre-planing approach follows the shape of the measured curve reasonably well, but over-estimates the magnitude of the resistance, while the planing approach over-estimates resistance by even more.

As a final comparison, the total resistance of the hull was predicted using the thin-ship code described previously to calculate the wave resistance, allied to a conventional approach using the ITTC 1957 correlation line for frictional resistance and the measured form factor of $1+\mathrm{k}=1.032$. It can be seen that the agreement is good up to around $4.0 \mathrm{~m} / \mathrm{s}$, apart from a slight under-estimation of the total resistance at $2.25 \mathrm{~m} / \mathrm{s}$. This is perhaps 
surprising since thin-ship theory is typically assumed to be most effective for ships with beam small compared to draft and length, which is clearly not the case for the Musto Skiff. At the higher speeds, when the boat starts to plane, the discrepancy starts to grow as the trim and sinkage start to change substantially; however the thin ship theory is still the best of these methods even at these higher speeds.
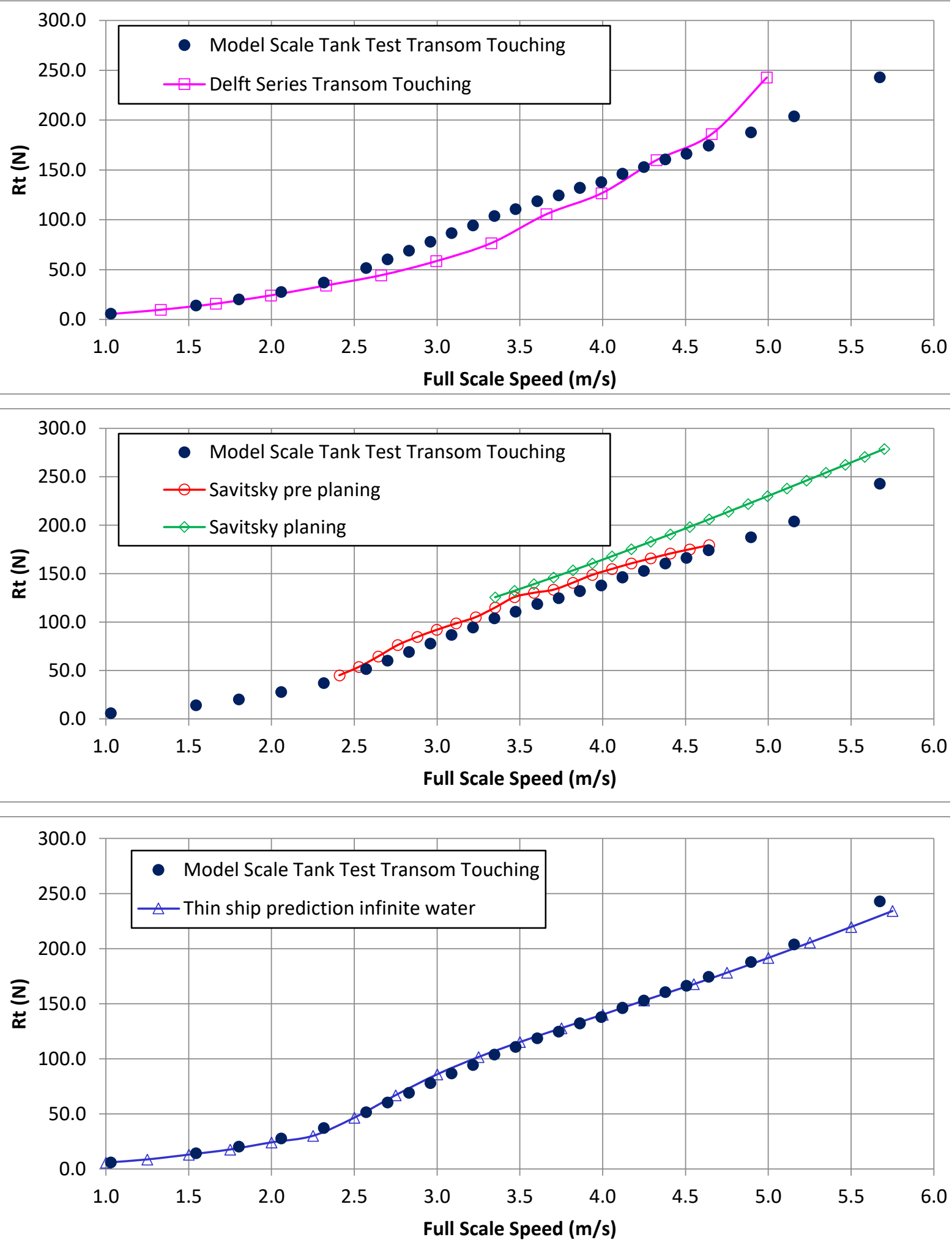

Figure 20. Predictions for the Musto Skiff from (a) Delft Series regression formula, (b) Savitsky's method, and (c) Thin ship theory; Transom touching condition 
The same set of calculations was carried out for the "chine level" case, for which the transom is immersed. Results are shown in Figure 21.
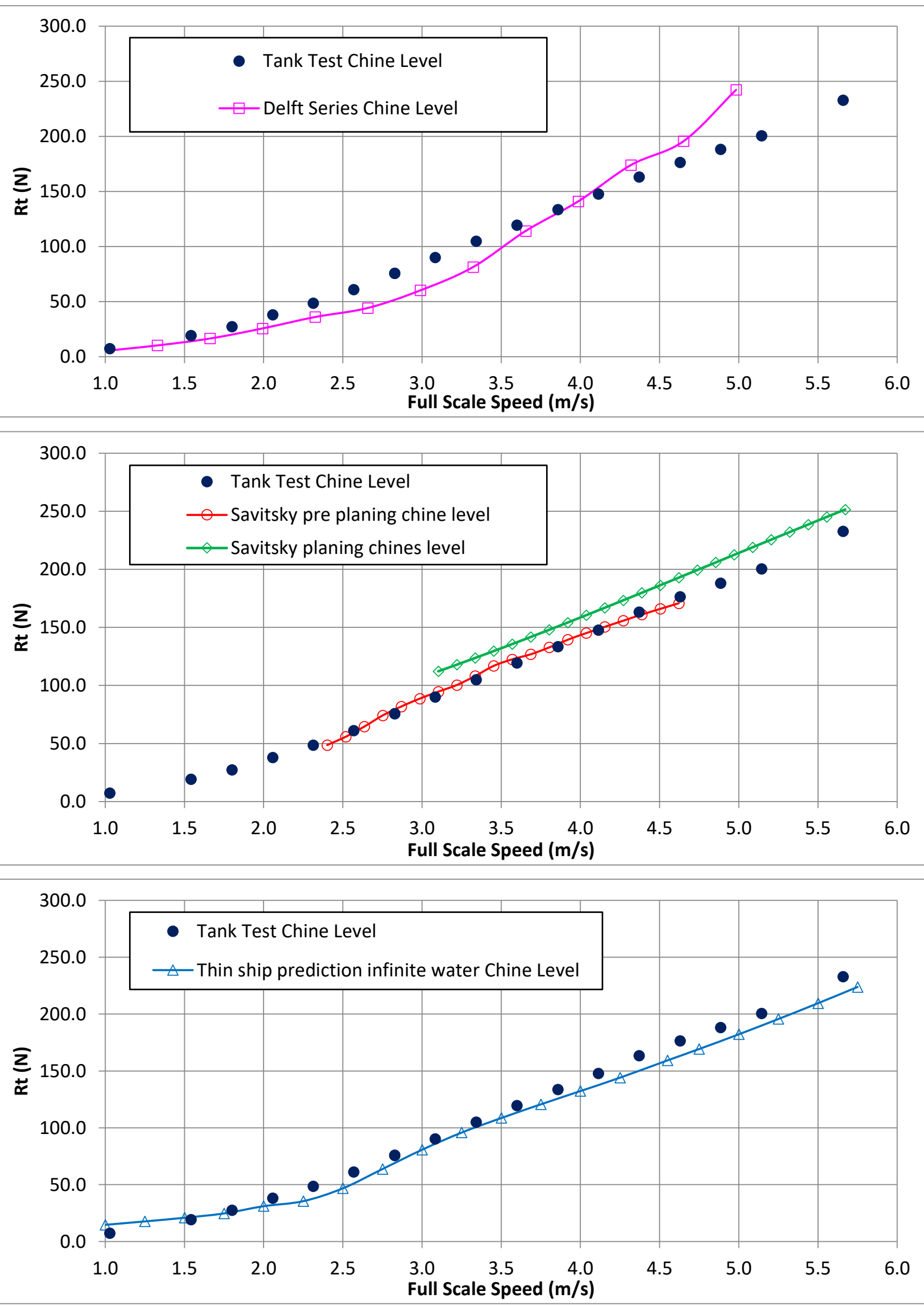

Figure 21. Predictions for the Musto Skiff from (a) Delft Series regression formula, (b) Savitsky's method, and (c) Thin ship theory; Chine Level condition 
It can be seen that the Delft and Savitsky planing approaches fail to predict the resistance with any great accuracy. However the Savitsky pre-planing approach is giving good agreement in this case in its applicable speed range, whilst the thin ship approach underpredicts the resistance.

\section{CONCLUSIONS}

A high-performance skiff hull has been tested using three different approaches: model scale tank testing, full-scale tank testing and open water testing. Results suggest that the open water testing produces reasonable results in comparison with the conventional techniques of model-scale tank testing once the data is carefully processed. A number of practical suggestions are made for improving open-water test procedures.

Less good agreement was initially obtained between the full-scale tests in the tank and the other two approaches at higher speeds, with finite depth effects apparently increasing the resistance. A correction approach is proposed using results from a linear thin-ship theory analysis to correct the wave resistance obtained from the tank; after this correction the agreement of the tank tests of the full scale hull with the model scale results is satisfactory.

A conventional model-scale tank tests yields a number of advantages, in particular the well-established data analysis processes, which suggest that this may yield the most reliable results with the minimum post processing, as well as allowing an increased speed range. The main disadvantage is the cost of model building. It can be seen that where a full-scale dinghy hull is available, testing either in open water or in a moderate scale towing tank can yield results which are satisfactorily comparable to those obtained from a conventional model-scale towing test with appropriate post-processing of data.

The tests show that the rudder has a complex effect on the resistance; tests also identify the impact of small waves, crew weight, and trim on the resistance.

Finally, comparison with the Delft series regression method, Savitsky's methods and a thin-ship theory show that both Delft and Savitsky planing methods are quite inaccurate for a hull form of this type. The thin ship method produces good agreement at low to moderate speeds when the boat is trimmed so that the transom is not immersed, but under-estimates the resistance with the transom immersed, whilst Savitsky pre-planing approach produces good agrement when the transom is immersed.

\section{ACKNOWLEDGEMENTS}

The authors would like to acknowledge the staff of the Kelvin Hydrodynamics Laboratory for their support during the tank test campaigns.

\section{REFERENCES}

Beaver B. \& Zseleczky, J. (2009). Full scale measurements on a hydrofoil international moth. Proceedings of 19th Chesapeake Sailing Yacht Symposium, March 2009, Annapolis, MD. USA.

Bertorello C., Bruzzone, D. Caldarella, S. Cassella, P. \& Zotti, I. (2003). From Model Scale to Full Size. Investigation on Turbulence Stimulation in Resistance Model Tests of High Speed Craft. Proceedings of 7th International Conference on Fast Sea Transportation (FAST 2003), 7-10 October 2003, Ischia, Italy.

Bethwaite, F. (1993). High Performance Sailing. Waterline Books, Shrewsbury, England. 
Carrico, T. (2005). A Velocity Prediction Program for a Planing Dinghy. Proceedings of 17 th Chesapeake Sailing Yacht Symposium, March 2005, Annapolis, MD. USA.

Claughton, A. R. (2015). SYRF Wide-Light Project, Sailing Yacht Research Foundation, http://sailyachtresearch.org/projects/wide-light-project.

Claughton, A. R. (2019). Private communication.

Couser, P. R., Molland, A. F., Armstrong, N. A. \& Utama, K. A. P. (1997). Calm Water Powering Predictions for High Speed Catamarans. Proceedings of Fourth International Conference on Fast Sea Transportation (FAST '97), 21-23 July 1997, Sydney, Australia.

Day, A.H. and Doctors, L.J.D. (2001). Concept Evaluation for High-Speed Low-Wash Vessels. Proceedings of 6th International Conference on Fast Sea Transportation (FAST 2001), 4-6 September 2001, Southampton, England.

Day, A.H., Campbell, I., Clelland, D. \& Cichowicz, J. (2011). An experimental study of unsteady hydrodynamics of a single scull. Proceedings of the Institution of Mechanical Engineers, Part M: Journal of Engineering for the Maritime Environment, Vol 225 Issue 3 282-294

Day, A. H. \& Nixon, E. (2014). Measurement and prediction of the resistance of a laser sailing dinghy. Transactions of the Royal Institution of Naval Architects Part B, International Journal of Small Craft Technology, Vol. 156, No. B1,11-20.

Day, A. H. (2017). Performance prediction for sailing dinghies. Ocean Engineering, 136, 6779.

Day, A. H., Cameron, P. \& Nixon, E. (2017). Moderate Cost Approaches for Hydrodynamic Testing of High Performance Sailing Vessels. Proceedings of 4th International Conference on Innovation in High Performance Sailing Yachts (INNOV'SAIL 2017), 28-30 June, Lorient, France.

International Towing Tank Conference (2017). ITTC Quality Systems Manual Recommended Procedures and Guidelines: Procedure 7.5-02-02-01: Resistance Test. $14 \mathrm{pp}$.

International Towing Tank Conference (2017). ITTC Quality Systems Manual Recommended Procedures and Guidelines: Procedure 7.5-02-05-01: High Speed Marine Vehciles Resistance Test. 19 pp.

Keuning, J.A., Katgert, M., (2008). A bare hull resistance prediction method derived from the results of the Delft systematic yacht hull series extended to higher speeds. Proceedings 1st International Conference on Innovation in High Performance Sailing Yachts, 29-30 May 2008, Lorient, France.

Levin, R. L. and Peter, J. (2014). CFD prediction of the effect of heel and trim on the resistance of an Olympic dinghy. Masters Thesis, Chalmers University of Technology, Gothenburg, Sweden.

Lunde, J.K., (1951). On the Linearised Theory of Wave Resistance for Displacement Ships in Steady and Accelerated Motion, Transactions of SNAME, Vol. 59, 25-85.

Radojcic, D. and Bowles, J. (2010). On high speed monohulls in shallow water. Proceedings of the 2nd Chesapeake Power Boat Symposium, 19-20 March 2010, Annapolis, MD., USA.

Savitsky, D. and Ward Brown, P. (1976). Procedures for Hydrodynamic Evaluation of Planing Boats in Smooth and Rough Water. Marine Technology Vol 13, No. 4 381-400.

Stenhouse R. (2007). K16 taking control. DVD copyright Richard Stenhouse . 
Tamura, K. (1972). Study on the blockage correction. Journal of the Society of Naval Architects of Japan, Vol 1972, Issue 131, 17-28.

Viola I. M., Enlander, J. and Adamson, H. (2014). Trim effect on the resistance of sailing planing hulls. Ocean Engineering, Vol. 88, 187-193.

Watin, S. (2007). 49er performance enhancement. Accessed online 01/04/2017: http://9eronline.com/

library/49er\%20Performance\%20Enhancement\%20Report\%20by\%20Simon\%20Watin.pdf 